\title{
The Japanese Wagyu beef industry: current situation and future prospects - A review
}

\author{
Takafumi Gotoh $^{1,2, *}$, Takanori Nishimura ${ }^{3}$, Keigo Kuchida $^{4}$, and Hideyuki Mannen ${ }^{5}$
}

* Corresponding Author: Takafumi Gotoh Tel: +81-99-285-8699, Fax: +81-99-285-8699,

E-mail: gotoh@agri.kagoshima-u.ac.jp

1 Department of Agricultural Sciences and Natural Resources, Faculty of Agriculture, Kagoshima University, Kagoshima, 890-0065, Japan

2 Kuju Agricultural Research Center, Faculty of

Agriculture, Kyushu University, Takeda 878-0201,

Japan

${ }^{3}$ Muscle Biology and Meat Science laboratory,

Research Faculty of Agriculture, Hokkaido University,

Sapporo 060-8589, Japan

${ }^{4}$ Obihiro University of Agriculture and Veterinary

Medicine, Obihiro 080-8555, Japan

${ }^{5}$ Laboratory of Animal Breeding and Genetics,

Graduate School of Agricultural Science, Kobe

University, Kobe 657-8501, Japan

ORCID

Takafumi Gotoh

https://orcid.org/0000-0002-9211-9740

Takanori Nishimura

https://orcid.org/0000-0002-1021-1763

Keigo Kuchida

https://orcid.org/0000-0001-8978-3299

Hideyuki Mannen

https://orcid.org/0000-0001-5627-7082

Submitted Apr 30, 2018; Revised May 30, 2018; Accepted Jun 5, 2018

\begin{abstract}
In Japan, Wagyu cattle include four Japanese breeds; Black, Brown, Shorthorn, and Polled. Today, the renowned brand name Wagyu includes not only cattle produced in Japan, but also cattle produced in countries such as Australia and the United States. In recent years, the intramuscular fat percentage in beef (longissimus muscle) from Japanese Black cattle has increased to be greater than $30 \%$. The Japanese Black breed is genetically predisposed to producing carcass lipids containing higher concentrations of monounsaturated fatty acids than other breeds. However, there are numerous problems with the management of this breed including high production costs, disposal of untreated excrement, the requirement for imported feed, and food security risks resulting from various viral diseases introduced by imported feed. The feeding system needs to shift to one that is more efficient, and improves management for farmers, food security for consumers, and the health environment for residents of Japan. Currently, we are developing a metabolic programming and an information and communications technology (ICT, or Interne of Things) management system for Wagyu beef production as future systems. If successful, we will produce safe, high-quality Wagyu beef using domestic pasture resources while solving the problems of how to utilize increasing areas of abandoned agricultural land and to make use of the plant-based feed resources in Japan's mountainous areas.
\end{abstract}

Keywords: Beef; Japanese Black; Wagyu; Marbling; Quality; Fatty Acid Composition

\section{INTRODUCTION}

In traditional Japanese cooking, highly marbled beef is a prized ingredient. Beef dishes have become increasingly popular, although rice continues to be the main ingredient in most dishes. As a result of this increasing demand for beef in recent years, the use of heifers and steers instead of bulls and an intensive feeding system, together with the genetic attributes of Japanese Black cattle, have resulted in greater fat deposition compared with British and other European breeds. Intramuscular fat improves beef quality in terms of juiciness, flavor and tenderness [1-3]. Therefore, marbling is an accepted indicator of meat quality and is assessed in abattoirs by meat graders in various countries including the United States, Australia and Japan. The upsurge in imports of food products such as rice, beef, and oranges after the Uruguay Round in 1991 had a marked impact on the Japanese beef market. Up until that point, moderately marbled beef was the highest grade available. However, Japanese beef farmers and the Japanese government started to aim for increasingly marbled beef following the Uruguay Round in response to the serious threat posed by cheaper, imported, leaner beef. More recently, marbling levels in Japanese beef (especially, sirloin) has increased, with intramuscular fat levels of up to $60 \%$ [4]. However, management of Wagyu beef farms faces significant challenges as a result of rising feed costs, and in Wagyu calf prices which have 
increased significantly as a result of the rapid decline in the number of Wagyu calf breeders as farmers' age and exit the industry.

All food including meat has three basic functions: i) nutrition, ii) taste, and iii) disease prevention. In Japan, the main traditional dish is rice, while beef is served as a side dish. Therefore, Japan has worked to develop the quality of beef rather than its quantity, as opposed to the approach in many foreign countries, where meat is consumed as a main dish. In Japanese cuisine, tender and tasty beef with much intramuscular fat and a bright red color are prerequisites for dishes such as sukiyaki.

Nowadays, biosciences have given us new perspectives on healthy eating. In the past, fat had a poor reputation for human health, even though fat has always been an important energy source for humans. More recently, however, fat has been reported as having fewer adverse effects on health than carbohydrates, especially simple carbohydrates [5]. Food containing high-quality protein rather than carbohydrates is also desirable for good health [6]. Thus, the Japanese beef market needs to reconsider the qualities of Wagyu beef sold in Japan. This paper reviews the current situation regarding the Japanese beef market and examines the future prospects for the Wagyu beef industry in Japan.

\section{ORIGINAL JAPANESE BLACK WAGYU BREED}

In Japan, Wagyu cattle include four Japanese breeds: Black, Brown, Shorthorn, and Polled. All of these breeds have played important roles locally and in the history of mixed farming systems, as well as creating synergies that exist between cattle and crops, especially in rice production.

One of the original Japanese cattle breeds, Mishima, which is thought to be a Japanese native, is bred on Mishima Island in Yamaguchi prefecture. The Mishima breed seems to have retained its native characteristics, and is considered to improve meat quality when crossed with other breeds. Mishima steers attained a mean \pm standard deviation body weight of $517 \pm 20$ $\mathrm{kg}$ at $35.8 \pm 0.5$ months of age [7], and generally weigh less than fattened Japanese Black steers at 26 months of age $[8,9]$.

In the early 1900s, Japan started to crossbreed native cattle with imported breeds such as Braunvieh and Simmental cattle from Switzerland, Ayrshire, Devon, and Shorthorn cattle from the United Kingdom, and Holstein cattle from Germany and the Netherlands to increase the size and meat yield of draft and beef cattle as the Japanese lifestyle shifted toward being more Western. Later, following a decline in meat quality and an excessive increase in body size, Japan stopped crossbreeding and started to intra-breed cattle, resulting in establishment of the Japanese Black breed in 1944. Since then, this breed has been used for improved meat production [7].
After World War II, farmers gradually began reducing the use of cattle as draft animals and industrial fertilizer, and in recent years, Japanese Wagyu cattle have been raised specifically for highly marbled beef production. The famous brand name Wagyu includes not only the Japanese Black cattle produced in Japan, but also crossbred Japanese Black cattle produced in countries including Australia and the United States. There are numerous studies on the quality and quantity of meat and on muscle physiology of Wagyu-crossbred and purebred Japanese Black cattle in foreign countries [1015]. In the present paper, the term Wagyu refers specifically to the Japanese Black breed.

The high levels marbling in beef produced by Japanese Black cattle has led to this breed comprising the greatest share of Japan's Wagyu cattle population $[8,9,16,17]$. Bulls that have been intra-bred to improve marbling score are an important resource particularly because artificial insemination is used in nearly all cattle breeding in Japan (Figure 1). The market for beef with high levels of marbling was markedly enhanced following the decision by the Uruguay Round in 1991 which allowed Japan to import foreign beef [17].

\section{FEEDING SYSTEM FOR JAPANESE BLACK CATTLE}

To produce beef that satisfies the requirements of the Japanese beef market, appropriate nutritional management is essential. Nutritional management programs must consider numerous factors including growth rate, feed efficiency, health, animal welfare, disease tolerance, and intramuscular fat accumulation. In Japan, animals are raised in group-fed pens using the standard system for marbled beef production [8] (Figure 2). Each prefecture in Japan has a recommended fattening system. Japanese Black cattle are usually fed a high-concentrate diet from 11 months to 30 months of age to induce greater accumulation of intramuscular fat, which is the most important goal of Japanese Black cattle farmers. During the finishing period in particular, the most common fattening method is to provide as much concentrate as possible and rice straw ad libitum. Overall, cattle are fed a high-energy diet twice or three times daily from 11 months of age until slaughter at 28 to 30 months of age. From 11 to 18 months of age, the diet comprises increasing amounts of concentrate (36.8\% to $86.4 \%$, formulated feed) and decreasing amounts of roughage (Jamboree [beer bran], hay, and rice straw). During the final stage from 18 months of age until slaughter, the diet comprises $86.4 \%$ to $84.2 \%$ concentrate and $13.6 \%$ to $15.8 \%$ roughage. All cattle have constant access to water and blocks containing minerals, salt, and a diuretic. Total feed consumption during fattening is normally 4,000 to $5,000 \mathrm{~kg} / \mathrm{head}$, and more than $90 \%$ of the concentrate used for fattening Japanese Black cattle is imported. 


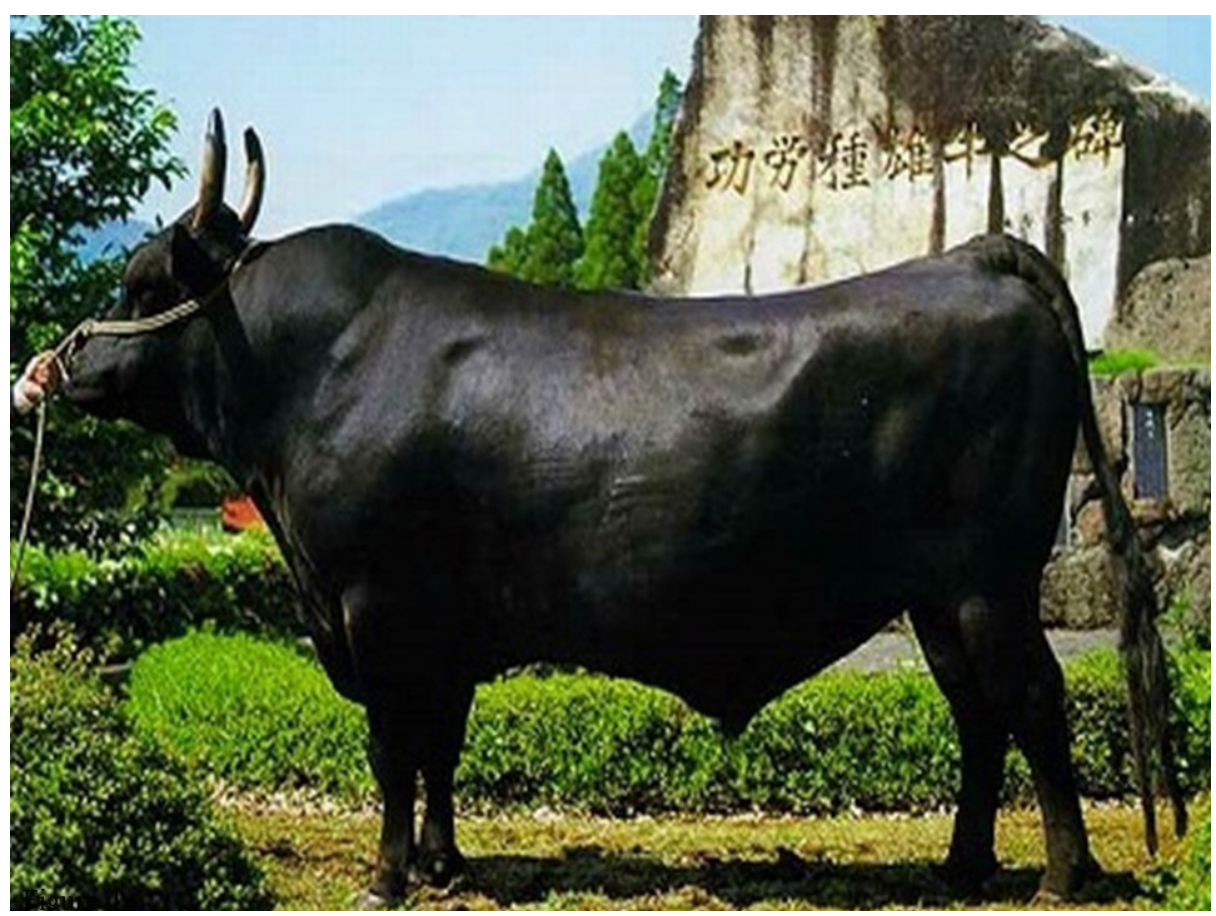

Figure 1. A Japanese Black bull (Itofuku, Oita prefecture) [16].

In recent years, Japanese farmers have considered manipulating vitamin A levels to improve marbling during fattening of Japanese Black cattle. Vitamin A derivatives (retinoids) play a key role in mammalian development and cell differentiation
[18]. In most cases, retinoic acid impairs adipocyte differentiation. Oka et al [19] and Nade et al [20] demonstrated the influence of vitamin A on beef quality in Japanese Black cattle. They suggested that regulating the serum vitamin A con-

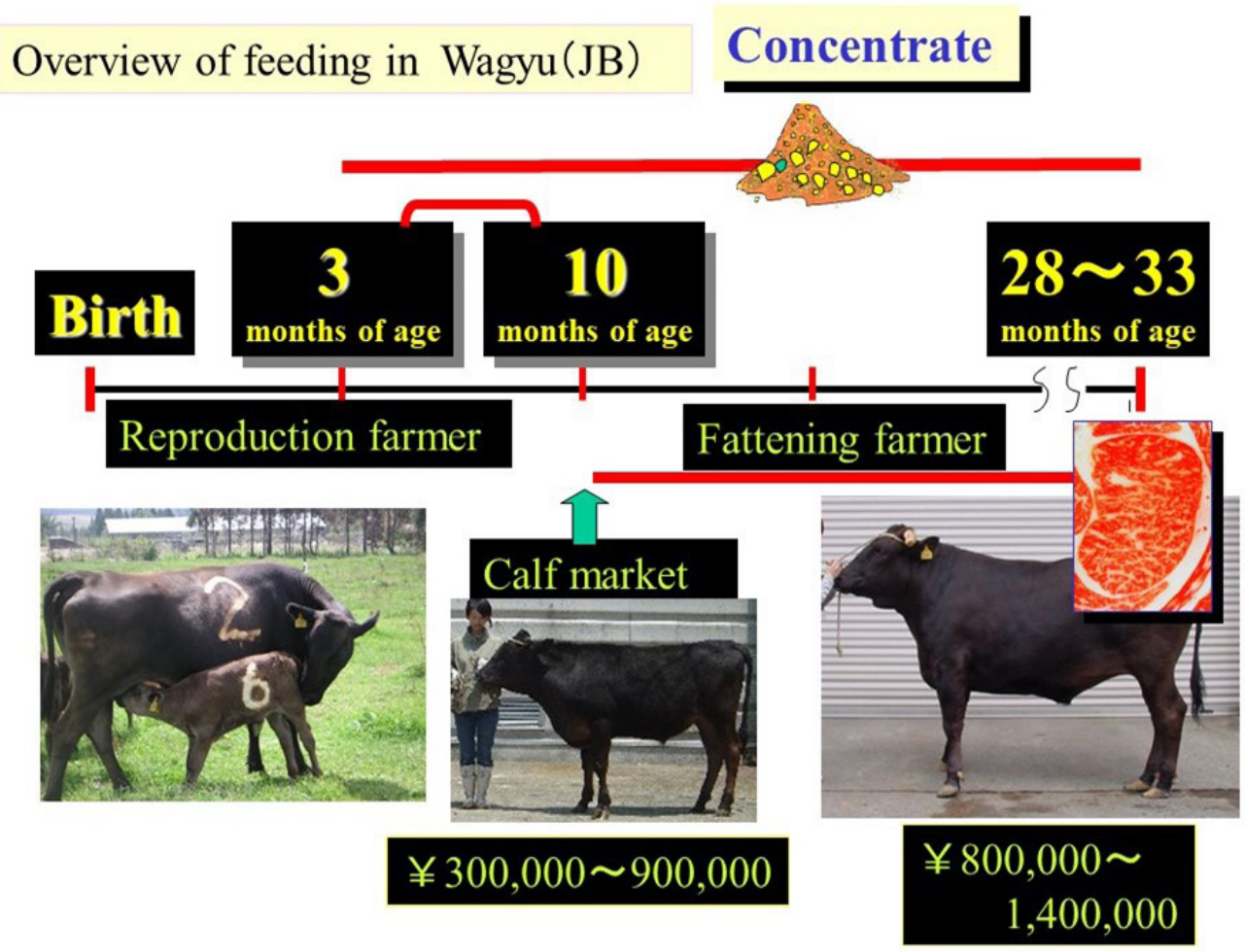

Figure 2. Overview of current Wagyu feeding system. 
centration could produce a higher marbling score without increasing subcutaneous fat in animals genetically predisposed to marbling. Currently, farmers keep the vitamin A concentration low only during the middle fattening period; during the finishing period, low levels of vitamin A often induce severe hepatic disease and swelling.

Japan experienced outbreaks of bovine spongiform encephalopathy (BSE) in September 2001 and foot and mouth disease (FMD) in 2000 and 2010. In recent years, Japan has been BSE and FMD-free. However, these earlier events caused huge economic damage and were suspected to be closely related to imported feed. In Japan, the use of animal protein has been prohibited as livestock feed since 2003. Regarding BSE, a traceability system started in beef production of Japan in 2004, and Japan is now better managing the safety of beef production. The feeding system in Japan needs to shift to one that is more efficient and provides better management for farmers, better food security for consumers, and a healthier environment for residents.

\section{GRADING SYSTEM FOR MARBLED BEEF IN JAPAN}

Carcasses of Japanese Black cattle and most of the other Japanese cattle breeds are evaluated by accredited graders from the Japan Meat Grading Association (JMGA) in accordance with the beef carcass grading standards. There are nearly 200 accredited graders in Japan. The present grading system was first established in 1988, and assigns both a yield grade (A, B, or C) and a meat quality grade (1 to 5) [21] (Figure 3 and Table 1). All beef carcasses in Japan are graded using the sixth to seventh rib section at least one hour after ribbing (Figure 4). Four items are independently evaluated: marbling; meat color and brightness; meat firmness and texture; and fat color, luster, and quality. The meat quality grade is then assigned based on the lowest grade for these four items.

In 1988, marbling levels were assigned in accordance with the beef marbling standard (BMS) using a plastic model made from silicone resin [22]. This standard was calculated based on the circumference and percentage of marbling particles in

\section{Beef Marbling Standard in Japan}

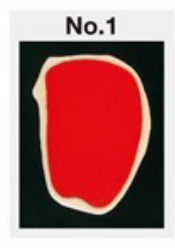

No or less marbling (no pictures)
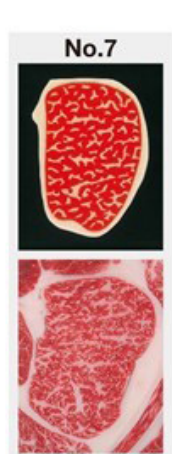

Beef Color Standard in Japan

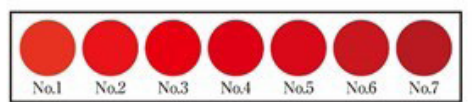

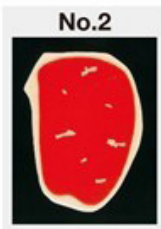
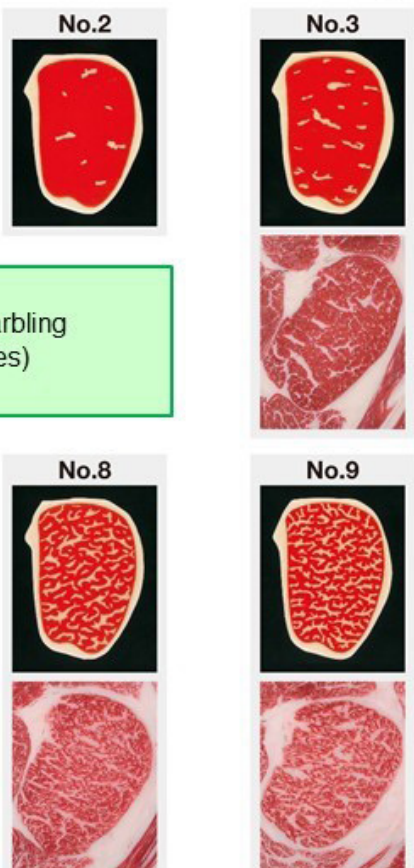
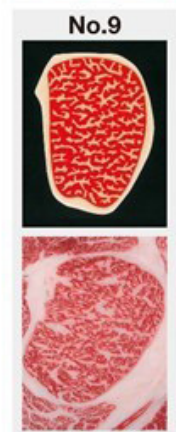

Beef Fat Standard in Japan
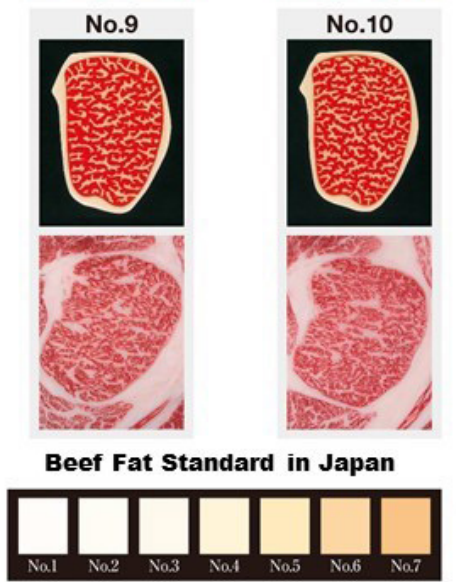
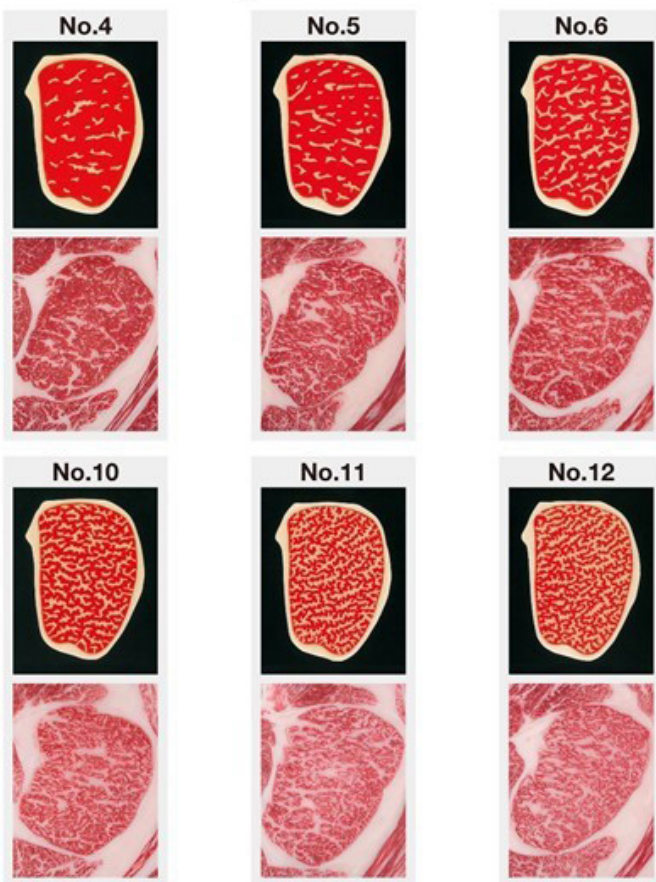

No.12
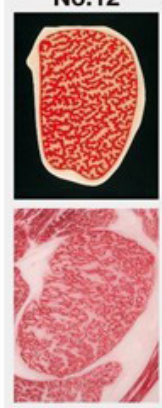

Public interest incorporated association

Japan Meat Grading Association

Figure 3. Official Beef Marbling Standard, including Beef Color Standard and Beef Fat Standard, from the Japan Meat Grading Association [21].

Table 1. Relationship between beef marble score (BMS) number and meat quality grade

\begin{tabular}{|c|c|c|c|c|c|c|c|c|c|c|c|c|}
\hline BMS no. & 1 & 2 & 3 & 4 & 5 & 6 & 7 & 8 & 9 & 10 & 11 & 12 \\
\hline
\end{tabular}




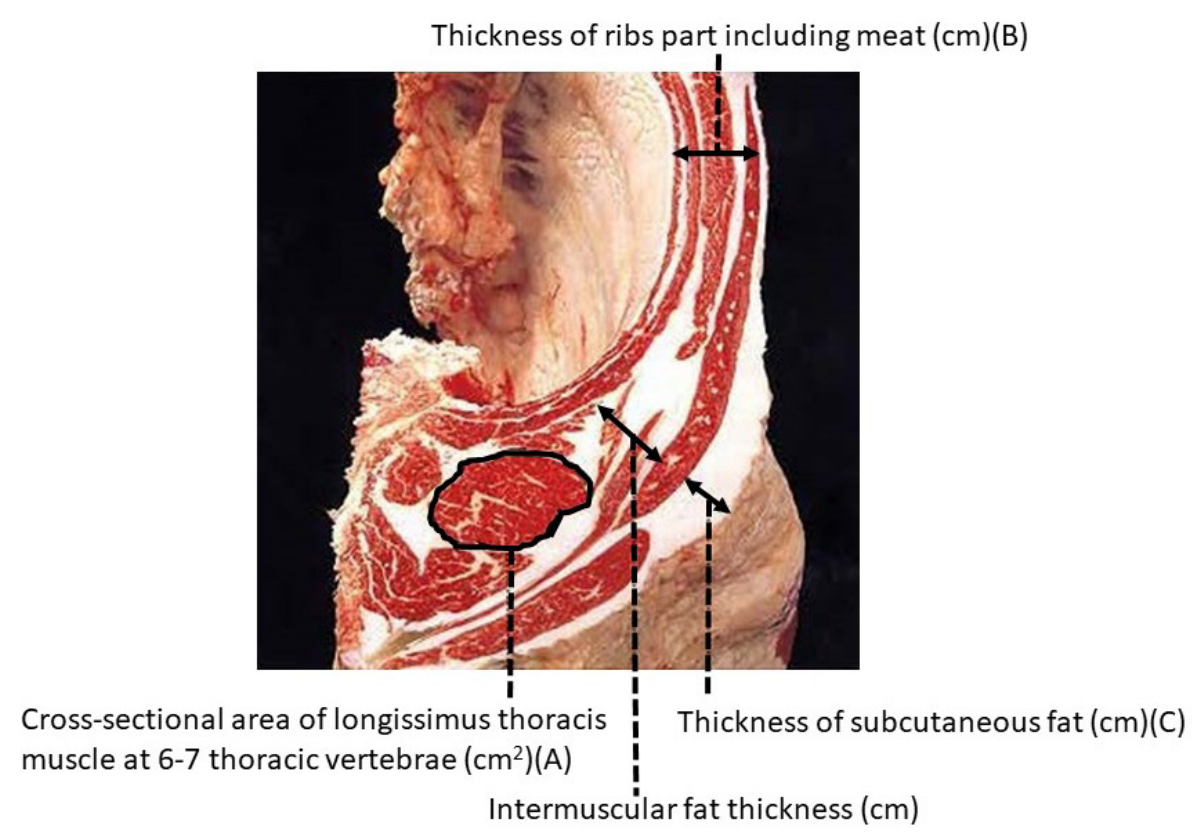

Figure 4. Body location used for carcass grading in Japan [21].

the rib eye section (longissimus dorsi). In October 2008, a new marbling standard using carcass photographs replaced the 1988 standard, and in March 2014, a newer marbling standard was implemented (Figure 3). Graders determine the BMS score (from 1 to 12 ) by comparing the actual carcass marbling with the marbling standard photograph. During this process, any larger areas of fat at the periphery of the rib eye are not considered as marbling in accordance with the Japa- nese grading system. In marketplace, the intramuscular fat content of the longissimus thoracis muscle at the sixth to seventh lumbar vertebrae where it is evaluated has increased dramatically during the period from 1988 to 2004, as shown in Figure 5, $6[4,16]$. Therefore, the grading association was forced to further modify the marbling standard in 2014. There are several strains of Japanese Black cattle, one of which is the Tajima breed. Highly marbled beef (with BMS greater than

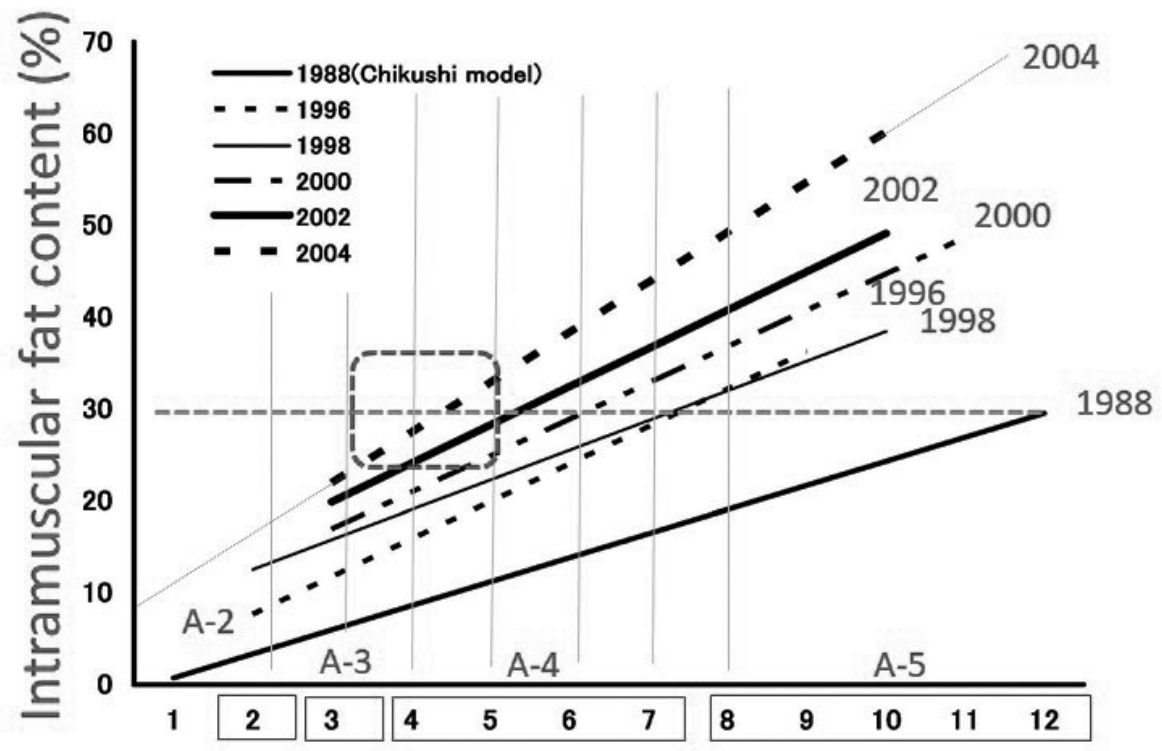

\section{Japanese Beef Marbling Standard numbers}

Figure 5. Correlation between Japanese Beef Marbling Standard numbers and crude fat content in the longissimus thoracis muscle from Japanese Black steers from 1996 to 2004. This figure has been modified based on the figure from the previous paper [4]. 

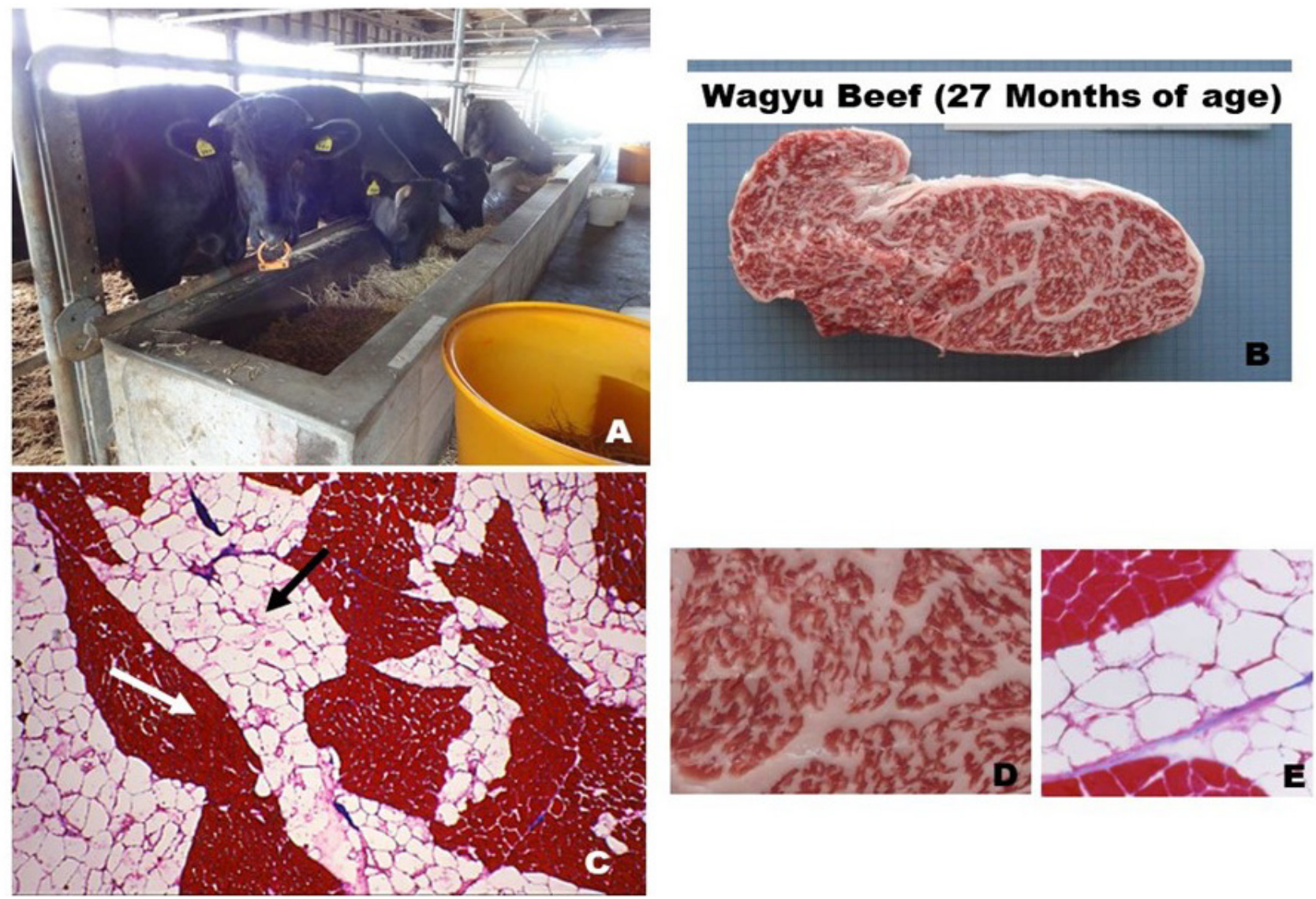

Figure 6. Meat produced by Japanese Black steers. (A) Marbled beef at the 12th thoracic vertebrae level of the longissimus thoracis muscle (BMS No. 7). (B) Macro appearance of marbled fat deposits. (C) Azan staining of transverse section (thickness: $10 \mu \mathrm{m}$ ) in the longissimus thoracis muscle of the highest-grade Japanese Black marbled beef. Myofiber bundles (white arrow) look like islands in a sea of adipose tissue (black arrow) [30]. (D) Magnified macro appearance of marbled beef. (E) Magnified appearance of Azan staining of intramuscular adipocytes [16].

No. 6) produced from Tajima cattle in Hyogo prefecture is the only beef that is approved for marketing as high-quality Kobe beef in Japan.

\section{BEEF SUPPLY, MARKETS AND ECONOMICS IN JAPAN}

In 2017, 2.5 million cattle were raised for beef production in Japan. Approximately 1.6 million of these were Japanese Black cattle (Ministry of Agriculture, Forestry and Fisheries [23], 21,000 were Japanese Brown cattle, and 25,000 were other Wagyu breeds. A further 834,700 non-Wagyu breed cattle were used for beef production (Holstein 313,000, F1 Wagyu-cross 521,600 , and others 100). The number of farms in Japan raising beef cattle is slowly declining. In 2017, there were 50,100 farmers producing beef, with each farmer raising 50 cattle on average. A total of $35.6 \%$ of cattle were raised on Kyushu (the main southern island) and $20.7 \%$ on Hokkaido (the main northern island).

The mean body and carcass weights of Japanese Black catthe at slaughter were $756 \mathrm{~kg}$ and $476 \mathrm{~kg}$, respectively, at 29.2 months of age, while the mean daily weight gain to slaughter was $0.77 \mathrm{~kg}$. Recently, the percentage of intramuscular fat in longissimus muscle from Japanese Black cattle has averaged more than 30\% [4,9] (Figure 5).

In 2017, the mean price of calves (9.1 months of age on average) at market was 653,827 yen (around 6,226 USD), while the mean price of carcasses in the beef market was 1,313,694 yen (around 12,511 USD). The average total cost of production per carcass was 1,054,763 yen (around 10,045 USD) [23].

In 2016, Japan imported 526,000 tons of beef, mainly from the United States, Australia, and New Zealand, while 324,000 tons of beef were produced in Japan, meaning that Japan imported around $62 \%$ of its beef requirements. Local beef production yielded revenue of about 13,552 million yen (129 million USD) (1,909 USD/ton) in 2016 (Table 2) [23]. In recent years, Japan has exported beef to several foreign countries such as the United States, Canada, Hong Kong, Macau, Mexico, New Zealand, Vietnam, Cambodia, Singapore, the Philippines, and, since 2014, the EU (Table 3). However, Japanese Wagyu beef is sold at higher prices than local beef in foreign countries. 
Table 2. Overview of Japanese beef imports in 2016

\begin{tabular}{llccc}
\hline & & $\begin{array}{c}\text { Amount } \\
\text { (ton) }\end{array}$ & $\begin{array}{c}\text { Sum } \\
\text { (million yen) }\end{array}$ & Ratio \\
\hline 1 & Australia & 273,675 & 157,208 & 54.4 \\
2 & USA & 192,128 & 109,730 & 38.0 \\
3 & New Zealand & 16,408 & 11,303 & 3.9 \\
4 & Canada & 13,458 & 5,566 & 1.9 \\
5 & Mexico & 7,355 & 3,947 & 1.4 \\
6 & Others & 1,360 & 1,010 & 0.3 \\
& Total & 504,384 & 288,764 & 100.0 \\
& * Average price (1,000 yen/ton) & & 572.5 & \\
\hline
\end{tabular}

*1,000 yen = about 10.6 USD (March, 2018). The data is from MAFF 2018.

\section{NUTRIENTS IN WAGYU BEEF, AND HEALTH}

The carcasses of Wagyu steers at 26 months of age comprise $47.7 \%$ muscle, $41.7 \%$ fat, and $10.6 \%$ bone, which is the highest level of fat compared with the carcasses of Belgian Blue cattle, Holstein and German Angus (though Belgian Blue are of no real relevance to marbled beef production) [5]. In samples of beef (longissimus muscle) from conventionally fattened Wagyu $(n=65)$, the mean percentages of moisture, crude fat, and crude protein were $47.1 \% \pm 5.8 \%, 38.4 \% \pm 7.7 \%$, and $13.9 \% \pm$ $1.9 \%$, respectively (National Livestock Breeding Center, unpublished data). High-quality Wagyu beef (longissimus muscle) consists of about $13 \%$ crude protein, $40 \%$ crude fat, and $47 \%$ moisture.

Beef is an important source of proteins, which are important for human health including in keeping blood vessels flexible and prevention of cerebrovascular disease [24]. An adequate protein intake also enhances our immune system [24]. If a person is lacking in protein, they could be prone to anemia, lose their resistance to diseases, and be more prone to stress [24]. One thirtieth of our body's protein content is exchanged every day. The proteins formed in the body consist of 20 kinds of amino acids, which play an important role in the biological regulation necessary to prevent disease. The amino acid score of beef is 100 , as beef contains all of the es-

Table 3. Overview of Japanese beef exports in 2016

\begin{tabular}{llccc}
\hline & & $\begin{array}{c}\text { Amount } \\
\text { (ton) }\end{array}$ & $\begin{array}{c}\text { Sum } \\
\text { (million yen) }\end{array}$ & Ratio \\
\hline 1 & Hong Kong & 659 & 4,017 & 29.6 \\
2 & Cambodia & 363 & 2,601 & 19.2 \\
3 & USA & 245 & 2,128 & 15.7 \\
4 & Singapore & 183 & 1,122 & 8.3 \\
5 & Thailand & 119 & 758 & 5.6 \\
6 & Others & 340 & 2,925 & 21.6 \\
& Total & 1,909 & 13,552 & 100.0 \\
& * Average price (1,000 yen/ton) & & 7,098 & \\
\hline
\end{tabular}

* 1,000 yen = about 10.6 USD (March, 2018). The data is from MAFF 2018 sential amino acids. High-quality Japanese Black beef contains all nine essential amino acids, and the protein absorption ratio from beef is about $97 \%$ [25].

Zembayashi et al [15] investigated the effect of breed and sex on the fatty acid composition of subcutaneous and intramuscular lipids in purebred Japanese Black and Holstein finishing steers and heifers, as well as crossbred Japanese Black, Holstein, Japanese Brown, and Charolais cattle. They reported that the Japanese Black is genetically predisposed to producing carcass lipids containing higher concentrations of monounsaturated fatty acids (MUFAs) than Holstein, Japanese Brown, and Charolais cattle. Sturdivant et al [26] also concluded that beef from purebred Wagyu cattle raised in Japan is rich in MUFAs. Gotoh et al [27] compared the intramuscular fatty acid composition of the longissimus muscle in 26-month-old Japanese Black steers and Holstein steers. The steers were reared and fattened using a standard fattening system with considerable amounts of concentrate based on a conventional Japanese fattening system, even though the normal fattening period for Holstein cattle is shorter (until they are just 20 to 22 months of age). The results showed a higher percentage of unsaturated fatty acid in Japanese Black steers than in Holstein steers. Gotoh et al [27] also compared the intramuscular fat content and intramuscular fatty acid composition of 21 major skeletal muscles from the same animals. Muscles from the Japanese Black cattle contained a greater proportion of various fatty acids, particularly C16:1, C18:1, and C20:1, and of MUFAs, compared with those from the Holstein cattle $(\mathrm{p}<0.001)$. In recent times, oleic acid (C18:1) has been shown to be associated with the Wagyu aroma. In Japanese Black cattle, the proportions of C18:0 and saturated fatty acids were much lower than in Holstein cattle $(\mathrm{p}<0.001)$ [27].

\section{HISTOCHEMICAL PROPERTIES OF WAGYU MUSCLE}

Meat is mainly skeletal muscle composed of several myofiber types, of which three are predominant; type I myofiber (slowtwitch oxidative), type IIA myofiber (fast-twitch oxidative glycolytic), and type IIB myofiber (fast-twitch glycolytic). The type and size of myofibers within specific muscles are important factors affecting meat quality because they influence many of the peri- and post-mortem biochemical processes in muscles [28]. Iwamoto et al [29] compared the histochemical fiber composition of Japanese Black, Japanese Brown, and Holstein cattle. A higher percentage of type IIB muscle fibers was observed in the Japanese Brown and Holstein breeds, while a greater percentage of type I or type IIA muscle fibers was observed in the Japanese Black cattle. Moreover, the Japanese Black cattle had larger type I fibers at a higher frequency than the two other breeds in the longissimus thoracis, semimembranosus, triceps brachii/caput longum, gluteus medialis, and 
vastus medialis muscles. Morita et al [7] compared the types of muscle fiber in the longissimus muscle between Mishima (a Japanese native) and Japanese Black cattle, including regional variations. The size of type I myofibers in the longissimus muscle were larger in the Mishima cattle, while the population of type I myofibers was less [7,30,31]. However, the percentage of type I myofibers in terms of total area was nearly identical between the breeds. Similar results were obtained in relation to other muscles. Solomon [32] and Rahelic and Puac [33] found that type I myofibers are larger in wild pigs than in domestic ones. They concluded that these results indicate that Mishima cattle have maintained certain histochemical myofiber properties that are characteristic of the native breed [30].

\section{HIGHLY MARBLED BEEF AND TENDERNESS}

Marbling (intramuscular fat) is one of the most important factors determining meat quality, especially texture and flavor. Japanese Black cattle are characterized by their ability to deposit very large amounts of intramuscular fat $[8,9,34]$. It has been shown that the shear force value of the longissimus muscle in Japanese Black steers decreases after 20 months of age, concomitant with the rapid increase in the longissimus crude fat content [3]. There was a significant negative correlation between the crude fat content and shear force value of the raw longissimus muscle in Japanese Black cattle after 20 months of age. Hence, a higher level of marbling is closely related to meat tenderness.

Why is highly marbled beef extremely tender? Nishimura et al [3] reported structural changes in the intramuscular connective tissues during fattening of Japanese Black steers using cell maceration and scanning electron microscopy. During the early fattening period from nine to 20 months of age, collagen fibrils within the endomysium in the longissimus muscle associate more closely with each other, the collagen fibers in the perimysium thicken, and their wavy pattern grows more regular [3]. These changes are closely related to the increased mechanical strength of the intramuscular connective tissue, resulting in toughening of the beef during this period. The shear force value of the longissimus muscle decreases after 20 months of age, concomitant with the rapid increase in the crude fat content. Scanning electron micrographs of longissimus muscles dissected from 32-month-old steers clearly showed that adipose tissue had formed between the muscle fiber bundles, the honeycomb structure of the endomysium was partially broken, and the perimysium had separated into thinner collagen fibers [3]. By contrast, in the semitendinosus muscle, which has a comparatively lower crude fat content, the structure within the intramuscular connective tissue remained rigid at 32 months of age and the shear force value of the muscle increased during the late fattening period from 20 to 32 months of age [3]. Thus, the development of adipose tissue in the longissimus muscle appears to disrupt the structure of intramuscular connective tissues and contributes to the tenderness of the highly marbled beef that is obtained from Japanese Black cattle [35] (Figure 7).

\section{GENES ASSOCIATED WITH WAGYU BEEF QUALITY}

In addition to its high level of marbling, Wagyu beef has a higher percentage of MUFAs than other breeds [36]. A higher percentage of MUFAs leads to a lower melting point for the fat, which contributes to the softness of bovine fat and improved beef flavor, and may decrease the circulating concentration of

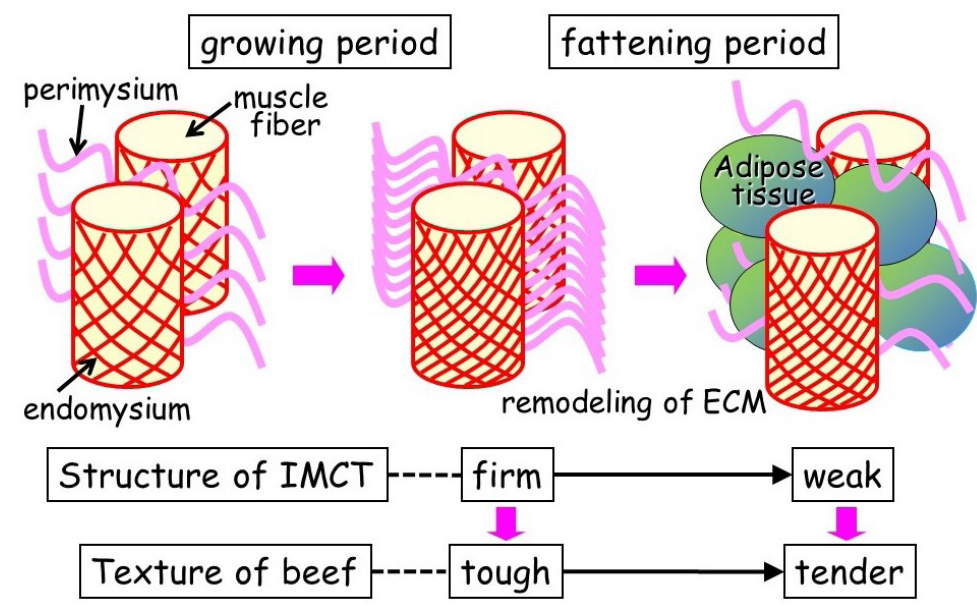

Figure 7. Effect of intramuscular fat deposition on the structure of intramuscular connective tissue (IMCT). With animal growth, collagen crosslinks become more stable, and the structural integrity of IMCT increases. These changes increase the mechanical properties of IMCT, contributing to the toughening of meat. The intramuscular fat deposits, mainly in the perimysium (between muscle fiber bundles), result in marbling. This causes the remodeling of the extracellular matrix and reduces the mechanical strength of the IMCT, contributing to the tenderization of beef [35]. 
low-density lipoprotein cholesterol [37-39]. Therefore, the fatty acid composition has recently become an important consideration in the beef industry, especially in Japanese Black cattle.

The fatty acid composition in cattle is much less dependent on diet because microorganisms within the rumen hydrogenate the majority of dietary unsaturated fatty acids, which are mostly absorbed as saturated fatty acids [40]. However, diet does still influence the bovine fatty acid composition $[41,42]$. Oka et al [43] demonstrated that different Japanese Black sire lines have significantly different fatty acid composition, suggesting that fatty acid composition is controlled by genetic factors such as lipid synthesis and fatty acid metabolism genes. The genes responsible for fatty acid composition have recently been identified in Japanese Black cattle.

Stearoyl-CoA desaturase $(S C D)$ was the first gene reported to be associated with fatty acid composition in beef [44]. This enzyme is responsible for converting saturated fatty acids into MUFAs in mammalian adipocytes. The composition of fatty acids stored in fat deposits reflects the earlier action of SCD on substrates such as stearic acid or palmitic acid [45]. Yang et al [46] reported interesting correlations between SCD enzyme activity and fatty acid composition in a survey of bovine adipose tissue.

The bovine $S C D$ gene has 1,080 nucleotides coding 359 amino acids. The nucleotide substitutions at bp 878 in the protein coding region lead to the replacement of the amino acid valine (V type) with alanine (A type) in the SCD peptide. In a study detailing the association between $S C D$ genotypes and fatty acid composition, the MUFA percentage differed significantly among the genotypes (high in type AA, medium in type $\mathrm{AV}$, and low in type VV) [44]. The melting point was also significantly different between the genotypes (high in type $\mathrm{VV}$, medium in type $\mathrm{AV}$, and low in type AA). The mean effects of gene substitution of the A allele on the MUFA percentage and the melting point of intramuscular fat were +0.805 and -1.03 , respectively. The genotypes explained $4 \%$ of the total variation in MUFAs and 3\% of the change in the melting point of intramuscular fat. The effects of genetics on fatty acid composition have been confirmed in many reports since then [47-49].

Since the report describing $S C D$, several candidate genes affecting fatty acid composition have been identified. Sterol regulatory element binding protein-1 (SREBP-1) regulates gene transcription activation by binding sequences contained in the promoters of downstream genes, including the $S C D$ gene, to the sterol regulatory element [50]. The intron polymorphism of SREBP-1 also affects the fatty acid composition in bovine adipose tissue [51]. Bovine fatty acid synthase (FASN) generates a multifunctional enzyme that regulates de novo biosynthesis of long-chain fatty acids in mammals [39]. Abe et al [52] revealed that the FASN genotypes significantly affect- ed the fatty acid composition of dorsal, intramuscular, and intermuscular fat in an $\mathrm{F}_{2}$ population generated from Japanese Black and Limousin cattle.

Additional genetic markers associated with fatty acid composition have been surveyed, primarily by Japanese scientists. The following genes were reported as either responsible or candidate genes affecting fatty acid composition: adipocytes fatty acid binding protein, liver X receptor $\alpha$, elongation of very-long-chain fatty acid 5 , fatty acid desaturase 2 , acetyl-CoA carboxylase- $\alpha$, and urotensin 2 receptor [53-57].

In general, traits in cattle such as the fatty acid composition have been considered polygenic. Although the adipogenic mechanism is extremely complicated, several genes have been identified and confirmed as being either associated with or responsible for the fatty acid composition in Japanese Black cattle. Representative genes such as $S C D$ and FASN have already been used as DNA markers to select elite sires for Japanese breeding programs. These genetic markers may also contribute to improvements in the beef industry and human nutrition worldwide.

\section{FUTURE PROSPECTS FOR THE JAPANESE BEEF INDUSTRY}

There are several ways to develop the Japanese beef production system, both in the near and more distant future. Here, we present two approaches: the government's recommendation for the near future; and the unique, more sustainable approach we are studying for the more distant future.

\section{Challenge of Japanese public institutes for shortening the feeding and fattening period}

As previously mentioned, the cost of Wagyu beef production in Japan is very high, accounting for more than $90 \%$ of the sale price. Moreover, it takes 30 months to complete the Wagyu fattening process. Recently, the price of calves at around 10 months of age has risen above 5,800 USD because of the shortage of breeding operations in Japan. Moreover, heavy dependence on imported feed has placed Japan in a precarious situation. Livestock-related epidemics, such as BSE and FMD, have also caused serious damage to the beef production industry in Japan. The Japanese beef production system's dependency on imported grain for feed is destined to amplify anxiety over food safety in the future, as a result of possible outbreaks of not only BSE but also of as yet unknown infectious diseases, because of the risk contaminated food being imported into Japan.

Many public livestock research institutes are trying to develop technologies to shorten the feeding period to less than 27 months of age while retaining meat quality in terms of a high level of marbling. Specifically, they are trying to start the fattening period earlier, for example from seven or eight months 
of age, rather than the current ten months of age [58]. However, it is difficult to shorten the fattening period by starting it earlier in life. Hence, Japanese Wagyu farmers are facing a considerable challenge, and are in need of a revolution in their feeding system.

\section{Potential of a new concept of grass-fed beef and} grazing feeding system and a new technology in Wagyu Beef contains high levels of important proteins related to essential amino acid (Protein score or amino acid score 100), and thus contributes significantly to human health and nutrition. The intensive feeding system that is necessary to produce marbled beef results in an increase of more than $30 \%$ in the fat content of carcasses [59]. However, it is unclear whether the desirability of beef produced by the Japanese Black breed is based only on the marbling characteristic or on other intrinsic factors as well. Scientific clarification of the skeletal muscle characteristics of Japanese Black cattle has long been sought.

Japan, as one of the world's developed countries, needs to consider the global food supply and security situation and shift towards the safe production of high-quality beef using domestic pasture resources, thereby freeing itself from the current dependence on imported feed. To achieve this laudable ideal, Japan need to focus on the use of pasture resources of mountains and foothills, as well as former agricultural land in Japan that has been abandoned (Figure 8).

Basically, cattle occupy an important ecological niche that capitalizes on the symbiotic relationship between fiber-fermenting ruminal microbes and mammalian demand for usable nutrients from ruminants. Beef cattle produce meat from grass resources as a source of carbohydrate and of protein after microorganisms in the rumen break down plant fibers that humans cannot digest. Our aim is for Japanese cattle to supply the beef requirements of the Japanese population by utilizing domestic grass resources on mountain slopes, foothills, and abandoned agricultural land. As much as $73 \%$ of the land area in Japan is mountainous. Rice, which is a staple food, is produced on flat areas, but there are large tracts of land that remain unused as $50 \%$ of the Japanese population is concentrated in only $14 \%$ of the total available land. Most of the Japanese population lives in big cities such as Tokyo and Osaka, while in the mountainous regions, the number of villages in which more than $50 \%$ of the inhabitants are over 65 years of age is rapidly increasing. To conserve these areas, it is important to retain the natural environment, including the endemic plants and animals.

Meanwhile, the situation regarding beef production in Japan is gradually changing. Consumers are concerned about environmental conservation, food security, health, sustainability, and animal welfare. Therefore, novel beef production systems that use domestic feed resources, especially domestic grass or pasture resources, should be developed. Future livestock production should consider innovative strategies, not only in terms of production efficiency, but also in relation to the incorporation of advanced biological and multiuse agricultural techniques into environmentally friendly systems [60]. Three innovative strategies have been recommended to achieve this aim: i) gaining a better understanding of the metabolic processes and intermediary mechanisms involved in rumination, enabling the development of strategies to improve microbial protein synthesis under several scenarios; ii) finding alternative solutions, perhaps in some lesser-known plants, to the problem of digestive limitations of legume feeding systems related to secondary compound contents and their bioactivity; and iii) including a wider range of domestic ruminant species and breeds in future research programs.

Recent research has discovered a unique phenomenon referred to as 'fetal and neonatal programming', which is based on the developmental origins of health and disease $(\mathrm{DOHaD})$ concept $[61,62]$. These studies have shown that alterations to the fetal and early postnatal nutrition and endocrine status may result in developmental adaptations that permanently change the structure, physiology, and metabolism of the affected animals during adult life. Ruminants occupy an important ecological niche that capitalizes on the symbiotic relationship between fiber-fermenting ruminal microbes and the mam-
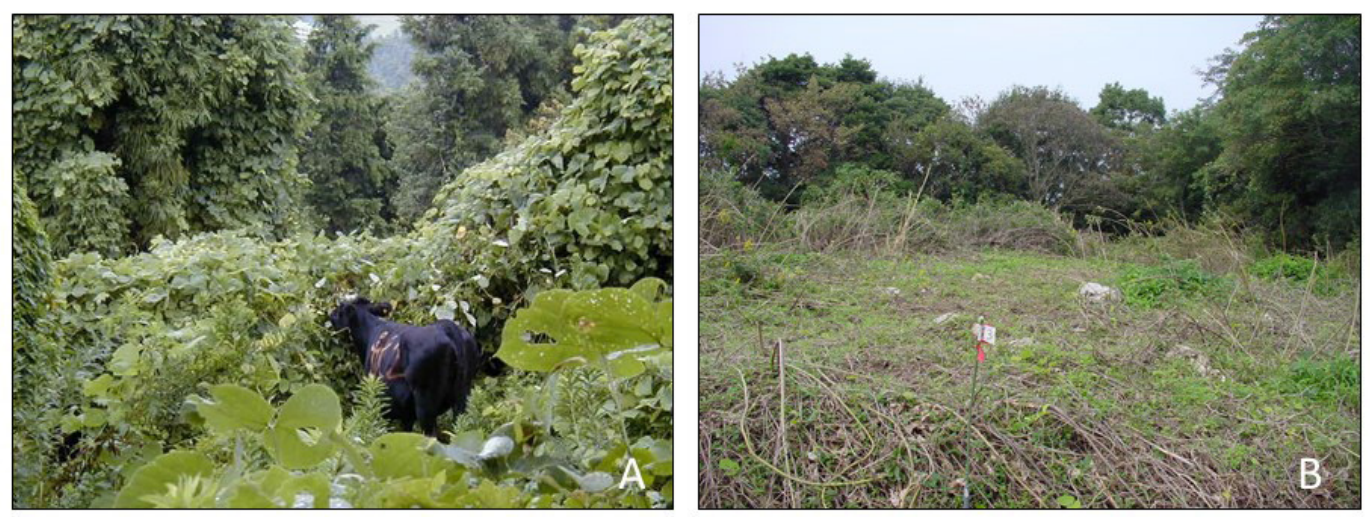

Figure 8. Cattle grazing on abandoned agricultural land: (A) when grazing commenced and (B) after three months [81]. 
malian demand for usable nutrients. The concept states that the nutritional environment and daily habits are strongly influenced by gene expression changes caused by epigenetic modification and altered phenotypes in animals. In a model experiment, it was shown that a mouse with intrauterine growth restriction (IUGR) had a low birth weight because of undernutrition during the fetal period. Following birth, the IUGR mouse rapidly gained weight and reached the same weight as a mouse that received normal nutrition during the fetal period (catch-up growth). When the IUGR animal was fed a high-fat diet, its body weight, adipose tissue, glucose tolerance, and insulin tolerance all increased significantly compared to non-IUGR mice [63].

The $\mathrm{DOHaD}$ concept covers the complex range of habits, environmental conditions, and physical conditions that respond to nutrition, and are transferred between generations. As for metabolic programming (imprinting), nutrition is the main driving force behind growth, physiology, and health in later life in the $\mathrm{DOHaD}$ concept. Metabolic programming is the conditioned postnatal nutritional exposure until the critical growth window is reached that leads to physiological varia- tions in adulthood $[64,65]$. The term 'metabolic programming' was first used in the medical field to explain how early nutrition manipulates the development of future diseases caused by adaptive responses during epigenetic processes (Figure 9).

Some $\mathrm{DOHaD}$ researchers are focusing on the metabolic programming (imprinting) during the neonatal period. A previous study of epigenetic programming by maternal behavior [66] reported that increased pup-licking, grooming, and arched-back nursing by mother rats altered the epigenome of their offspring at a glucocorticoid receptor gene promoter in the hippocampus. This indicated that a pup that was well cared for by its mother showed increased stress tolerance because of the epigenetic regulation of glucocorticoid receptor expression, thus demonstrating the effect of maternal care on stress responses in the offspring. Another example of neonatal programming (imprinting) demonstrated an altered pancreatic islet function in adult rats as a result of consuming formula (milk replacement) during the suckling period. This resulted in hyperinsulinemia during the post-weaning period, and eventually led to the development of obesity in adult life $[67,68]$. In the islets of the high carbohydrate group, the mRNA ex-

\section{Strategy: potential of epigenetics for application?}
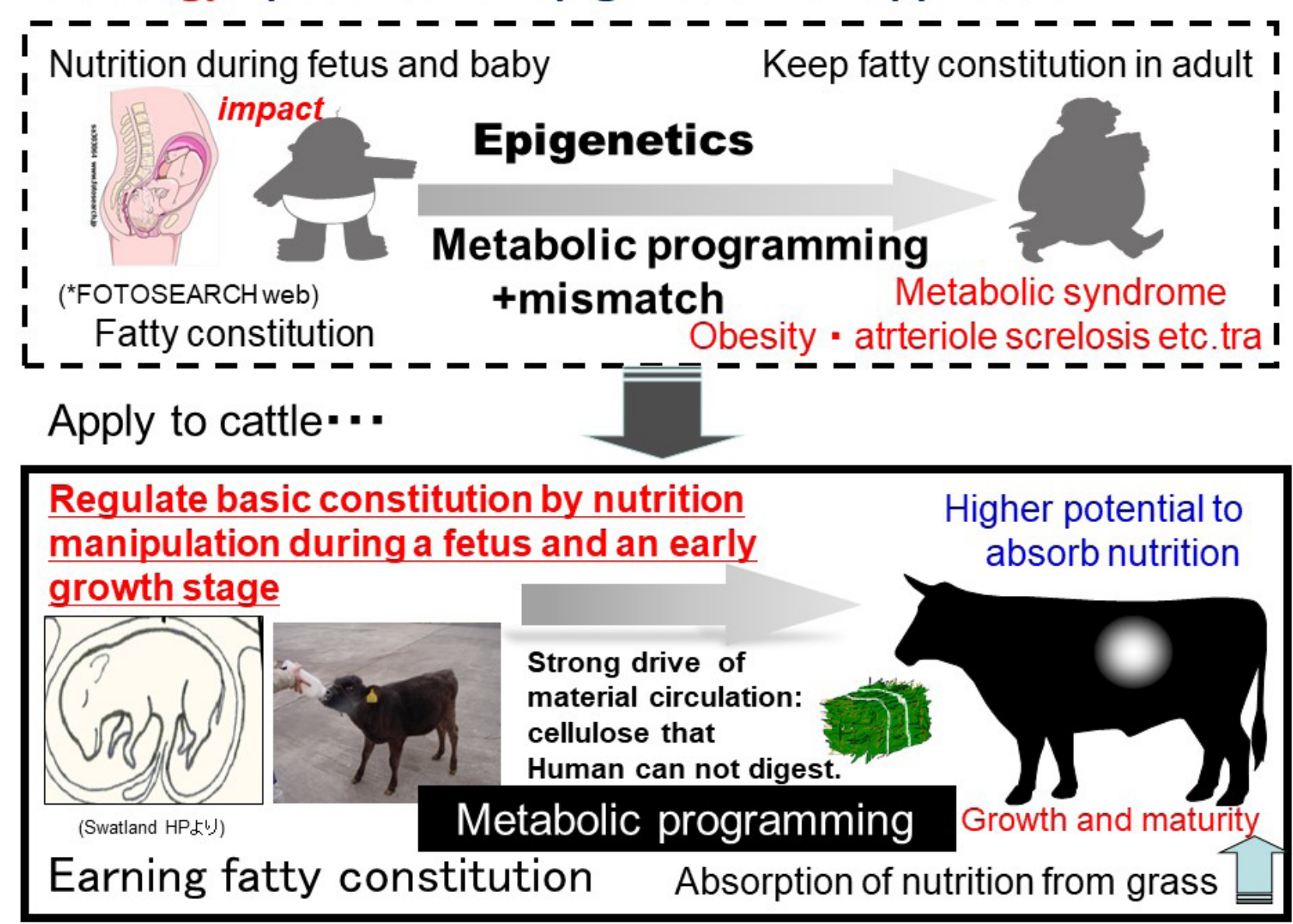

Figure 9. Application of metabolic programming to beef production. 
pression of preproinsulin, somatostatin transcription factor-1, upstream stimulatory factor-1, stress-activated protein kinase-2, phosphatidylinositol kinase, and glucose transporter-2 was increased. Finally, Waterland et al [69] investigated methylation changes during the postnatal development of mice, revealing the role played by DNA methylation in mammalian differentiation. They suggested that the critical window for mammalian epigenetic development extends well beyond the early embryonic stage of life.

It appears that the $\mathrm{DOHaD}$ concept is based on epigenetics. The term 'epigenetics' was proposed by Waddington several decades ago to describe the study of "the causal interactions between genes and their products which bring the phenotype into being" [70]. Epigenetics is the study of mitotically heritable alterations in gene expression potential that are not caused by changes in the DNA sequence [71], and falls into three main types: DNA methylation, histone modification, and noncoding microRNA $[70,72,73]$. Epigenetics is a key mechanism allowing for phenotypic plasticity within a fixed genotype. Epigenetic modifications can result from internal or external stimuli, thus allowing fetal gene expression to best respond to environmental nutritional stimulation [74]. DNA methylation and histone modification are both highly dependent on nutrition. Previously, the main factors influencing nutrient partitioning between the dam and fetus were shown to include the age of the dam, the number of fetuses, production demand, and environmental stressors [73]. These influence both the intensity and timing of gene expression during cell differentiation. DNA methylation is highly correlated with gene expression. In mammalian DNA, the specific pattern of $\mathrm{CpG}$ dinucleotide methylation varies among cells of different tissues. The maintenance of methylase activity allows specific methylation patterns to be transmitted to progeny cells with high fidelity, suggesting a relatively simple cell memory mechanism [64]. We aim to apply this concept to beef production (Figure 9).

Impact of the application of neonatal programming on body weight and intramuscular fat in Wagyu and Holstein cattle

Metabolic programming of Wagyu and Holstein steers during early growth has been investigated (Figure 10). Scheffler et al [75] reported that early weaning and high-concentrate feeding for 148 days, followed by grazing and feedlot entry, did not improve feedlot performance. However, this management scheme improved the marbling score and increased the hot
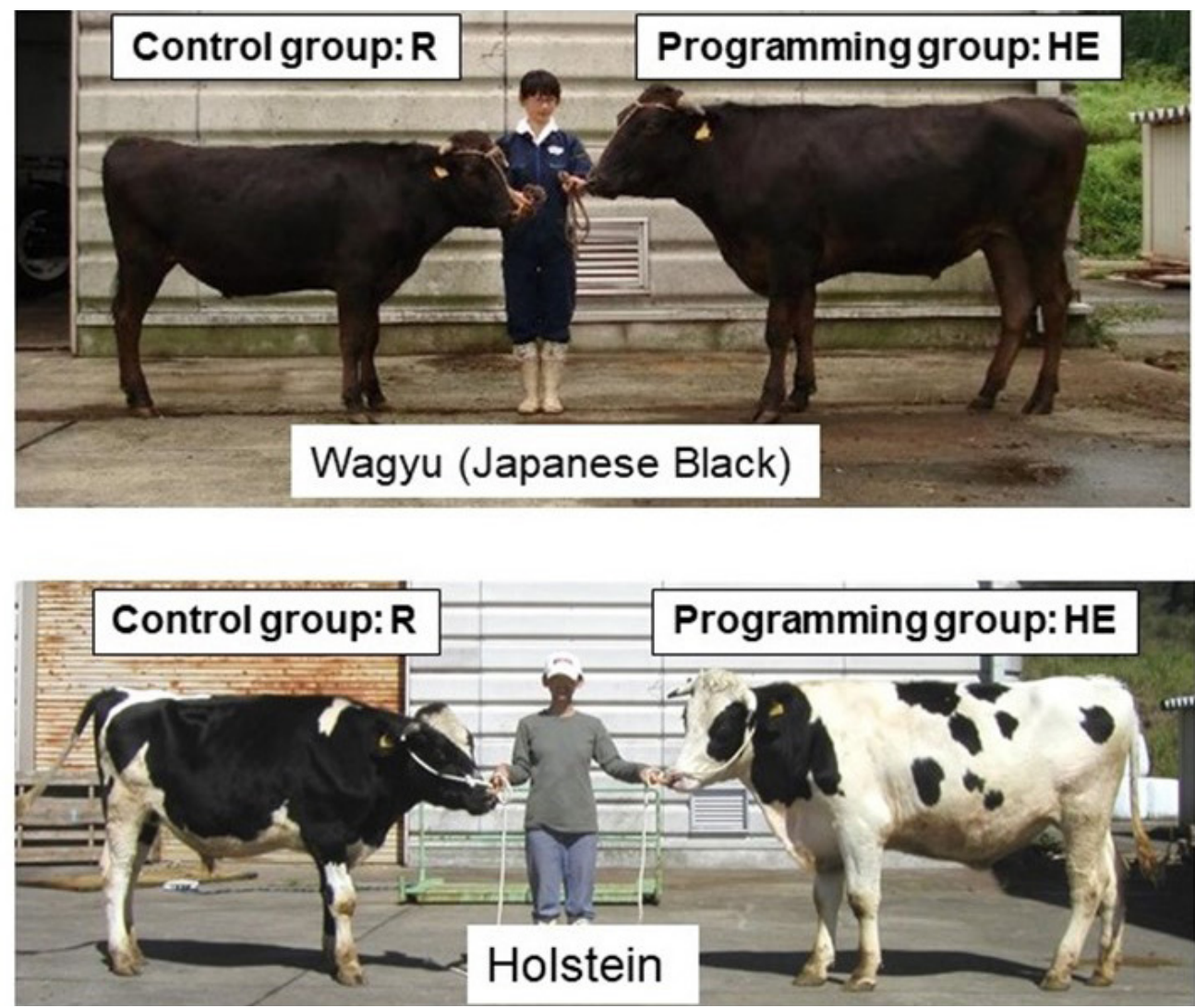

Figure 10. Comparison of body sizes between the Roughage (R) and Imprinting (HE) groups of Wagyu and Holstein steers at 26 months of age. Wagyu steers were either fed only roughage from weaning until 26 months of age (left) or fed concentrate (with access to roughage ad libitum) from three to ten months of age and only roughage from 11 to 26 months of age (right). IMF, intramuscular fat content. * Significant difference between groups $(p<0.05)$ [79]. 
carcass weights compared with those of conventionally weaned and backgrounded calves, although there were no significant differences in the lipid content between the conventionally weaned (4.5\%) and early weaned groups (6.0\%). Wagyu steers accumulate high levels of intramuscular fat. Our laboratory recently estimated the impact of various feeding protocols on growth (body weight) and IMF development in Wagyu and Holstein steers by comparing animals fattened using one of three different feeding programs prior to slaughter $[9,76,77]$. Wagyu and Holstein steers were nursed either conventionally or artificially until two to three months of age and then divided into three groups: Roughage ( $\mathrm{n}=7$ and $\mathrm{n}=4$ for Wagyu and Holstein steers, respectively), Imprinting ( $n=7$ and $n=5$, respectively), and Concentrate ( $\mathrm{n}=6$ and $\mathrm{n}=5$, respectively). The Roughage group was fed only roughage until ten months of age. The Imprinting group was fed a large amount of concentrate (more than $2.5 \%$ of their body weight) and given $a d$ libitum access to hay until ten months of age. From 11 until 26 months of age, both groups were fattened with hay alone. The Concentrate group was intensively fattened with concentrate from three until 26 months of age. Percentages by volume of intramuscular adipose tissue in the longissimus muscle were measured. The body weight of the Wagyu $(472 \pm 42 \mathrm{~kg})$ and Holstein steers $(605 \pm 31 \mathrm{~kg})$ in the Imprinting group was 1.3fold higher than that of the Wagyu $(357 \pm 25 \mathrm{~kg})$ and Holstein steers $(484 \pm 46 \mathrm{~kg})$ in the Roughage group (Figure 10). Furthermore, the increases in body weight of the steers in the

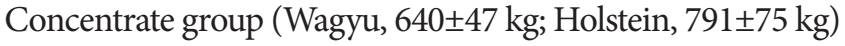
relative to the steers in the Roughage group were 1.8- and 1.6fold in the Wagyu and Holstein steers, respectively. Meanwhile, the increases in the IMF of the steers in the Imprinting group (Wagyu, $10.3 \% \pm 1.7 \%$; Holstein, $3.4 \% \pm 1.3 \%$ ) relative to those of the steers in the Roughage group (Wagyu, $6.2 \% \pm 3.7 \%$; Holstein, $1.3 \% \pm 0.1 \%$ ) were 1.6 - and 2.6-fold in the Wagyu and Holstein steers, respectively. The increases in the IMF of the Concentrate group (Wagyu, 32\% $\pm 3.9 \%$ Holstein, $17 \% \pm 1.8 \%$ ) relative to the Roughage group were 5.1- and 13.0-fold in the Wagyu and Holstein steers, respectively. These findings suggest that the impact of nutrition during fattening is greater than that of early nutrition, especially for IMF, and that this effect is greater in Holstein steers than in Wagyu steers, although the basic potential to accumulate IMF differs between Wagyu (6.2\%) and Holstein steers (1.3\%). However, in the case of fattening with a roughage-only diet, early nutrition affects the final body weight ( $30 \%$ increase) and IMF content (60\% to $160 \%$ increase) at slaughter.

Additionally, using the same sample of Wagyu cattle, we calculated the environmental impacts of each feeding system based on the $\mathrm{CO}_{2}$ equivalents per kilogram of Wagyu beef yield. The environmental impacts of each feeding system in terms of $\mathrm{CO}_{2}$ equivalents (eq) were about $6.10,9.32$, and 2.04 tons of $\mathrm{CO}_{2}$ eq for the Imprinting, Concentrate, and Roughage groups, respectively. The environmental impact of the Imprinting group was 30\% less than that of the Concentrate group [78].

\section{Progress of metabolic programming trial for Wagyu beef production}

We applied metabolic programming with intensive nursing and fattening until 30 months of age using grass (Figure 11) [79]. Wagyu steers were randomly allocated to one of two groups. The high-energy group (HE: $n=12$ ) was metabolically imprinted by intensified nursing (maximum intake of $1.8 \mathrm{~kg} / \mathrm{d}$, crude protein $26 \%$, fat $25.5 \%$ ) until three months of age and was then fed a high-concentrate diet from four to ten months of age. In contrast, the roughage group $(\mathrm{R}: \mathrm{n}=11)$ was nursed conventionally (maximum intake of $0.6 \mathrm{~kg} / \mathrm{d}$, crude protein $26 \%$, fat $25.5 \%$ ) and was fed only roughage (orchardgrass hay) ad libitum from four until ten months of age. A milk replacement containing higher levels of protein and fat was fed to each group. From ten months of age, both groups were fed only roughage ad libitum until 14 months and then all animals were put out onto the same pasture and grazed until they were 20 months old. After that, both groups were fed only roughage ad libitum from 21 to 31 months and then slaughtered. Fresh tissue biopsies were collected from the longissimus muscle at three, 10, 14, 20, and 30 months of age. The expression of peroxisome proliferator-activated receptor gamma 2 $(\operatorname{PPAR} \gamma 2)$, protein arginine methyltransferase 5 (PMRT5), and leptin [80] was investigated in each longissimus muscle (LM) sample by quantitative polymerase chain reaction analysis. After slaughter, the weights of the muscle, fat, bone, and other carcass components were measured in both groups. Steak samples from the LM were collected from all animals. Intramuscular fat content and fatty acid composition were analyzed. Additionally, the concentration of vitamin E in the LM was measured. The average live weight at 30 months of age was significantly higher in the HE group $(576 \pm 40 \mathrm{~kg})$ than in the R group (527 $\pm 36 \mathrm{~kg} ; \mathrm{p}<0.05$; Figure 11). The carcass weight and total carcass fat were both significantly higher in the HE group than in the R group ( $\mathrm{p}<0.05)$. Similarly, there was a tendency for the HE group to have a greater muscle weight than the R group $(p=0.06)$, meanwhile there was no significant difference of the ration of total muscle weight to carcass weight between two groups. Eighteen primary muscles were investigated, and the following muscles were significantly larger in the HE group than in the R group: infraspinatus, serratus ventralis cervicis, serratus ventralis thoracis, supraspinatus, and semimembranosus $(\mathrm{p}<0.05)$ though there was now significant difference of ratio of each muscle weight to total muscle weight between two groups. In relation to fat accumulation, the subcutaneous isoform of PPAR $\gamma 2$ is a master regulator of adipogenesis. The expression of PPAR $\gamma 2$ was significantly higher in the HE group than in the R group at 3 and 30 months of age ( $p<0.05$ and $p<0.01$, respectively). PMRT5 is an 


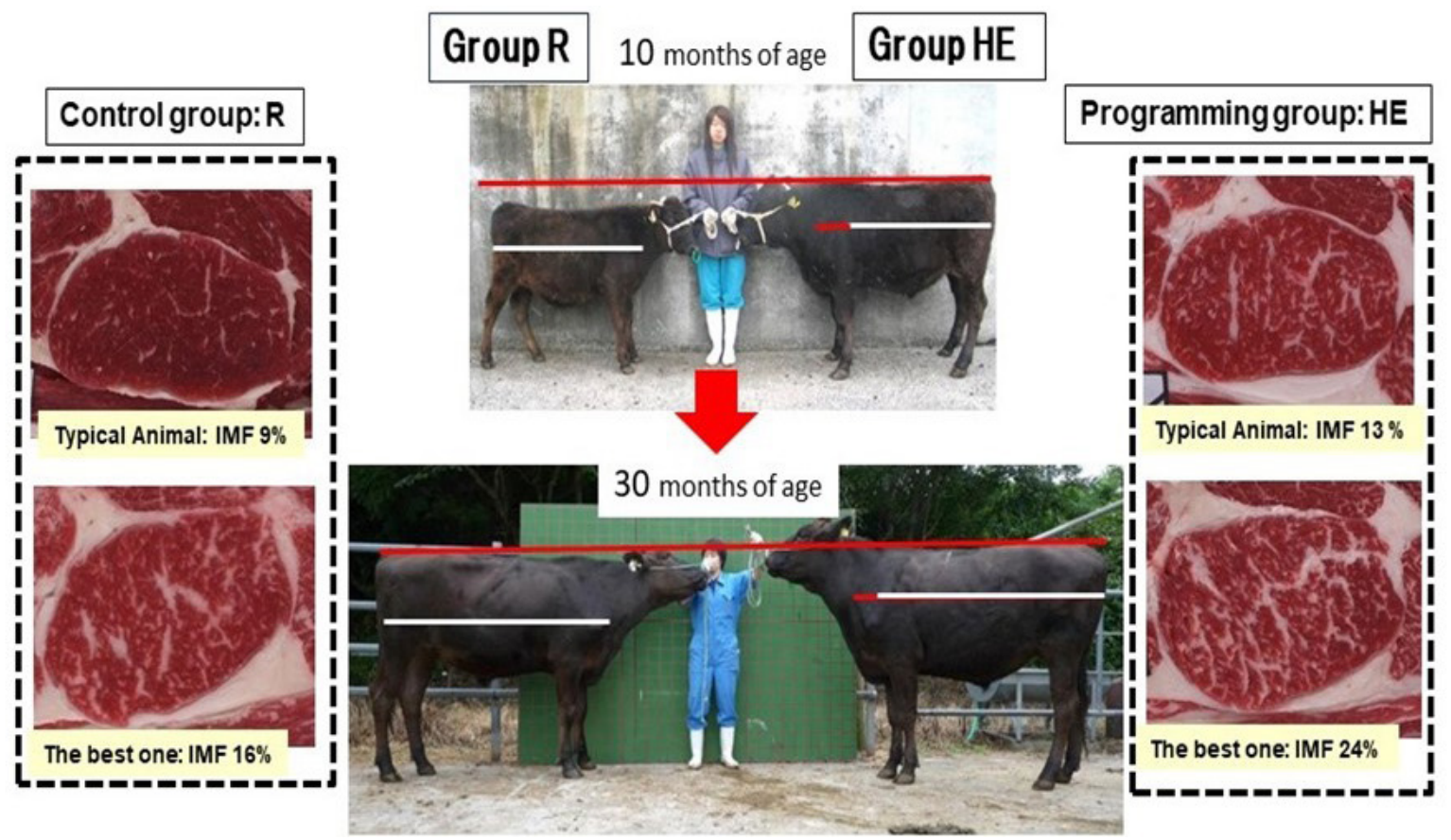

Figure 11. Comparison of body sizes between the Roughage (R) and Imprinting (HE) groups of Wagyu steers at ten and 30 months of age. Wagyu steers were either fed only roughage from weaning until 26 months of age (left) or were nursed with high-fat milk replacement and fed concentrate (with access to roughage ad libitum) from four to ten months of age and then fed only roughage from 11 to 30 months of age (right). IMF, intramuscular fat content. * Significant difference between groups $(p<0.05)$. Comparison of marbling appearance and intramuscular fat content between HE and R groups at slaughter age. HE group: $n=12$. $R$ group: $n=11 .{ }^{*}$ Significant difference between groups $(p<0.05)[79]$.

epigenetic signaling gene associated with adipogenesis and similarly expressed with the CCATT/enhancer binding proteins (C/EBP) $\alpha$, PPAR $\gamma 2$. The expression of PMRT5 was also significantly higher in the HE group than in the R group at three and 30 months of age ( $<<0.05$ and $p<0.01$, respectively). The leptin gene, which encodes an adipokine secreted by white adipocytes that plays an important role in the regulation of bodyweight, food intake inhibition, and energy expenditure, was expressed at significantly higher levels in the HE group than in the R group at 10,14 , and 30 months of age $(p<0.01$ in all cases). Muscle samples from the HE group contained much higher proportions of the fatty acids C18:1, C18:2, and C20:1, unsaturated fatty acids, and MUFAs than those from the R group $(\mathrm{p}<0.01)$. Even though all animals were fattened with the same roughage since 11 months of age, the fatty acid composition of the LM differed between the groups. This change in fatty acid composition may have been caused by the metabolic imprinting effect of a high feeding level during early growth. These findings indicate that PMRT5 acts as a coactivator for gene expression in adipogenesis and promotes adipogenic differentiation. Between-group differences, including different expression of PPAR $\gamma 2$ and leptin, may indicate metabolic changes in the animals in the HE group as a result of metabolic imprinting. In contrast to the results of Scheffler et al [75], the bodyweights of the cattle in each group were similar. However, the intramuscular lipid content in the meta- bolically imprinted cattle in Scheffler's research (crossbreeds with Angus sires that were feedlot fattened) was 6.0\%, while metabolically imprinted Wagyu had 13\% intramuscular lipid content. Our results clearly demonstrated that metabolic imprinting through early nutrition had a strong and lasting effect on the expression of adipogenesis-related genes in Wagyu cattle. In this experiment, an increased level of nutrition during early growth strongly affected later mRNA expression and skeletal muscle development. Growth and meat quantity and quality were markedly different between the HE and R groups. This may have been caused by the effect of metabolic imprinting induced by feeding large volumes of a high-fat milk replacement and subsequent concentrate feeding during the post-weaning period (until 10 months of age). However, we would need to undertake further research into the detailed mechanisms underlying these effects.

\section{THE POTENTIAL FOR ICT MANAGEMENT OF WAGYU FATTENING BY GRAZING}

In order to combine Wagyu production using grazing with metabolic programming, we created an IoT system to monitor the feeding of grazing cattle that includes the following elements: i) actuators including an audio player, feeder, and stanchion; ii) wireless nodes with Wi-Fi connectivity to control the actuators; and iii) IP cameras (a network camera having 
internet protocol (IP) address) that are connected to a wired network via Wi-Fi. With this system, farmers can use a smartphone to call grazing cattle using the audio player towards the IP camera and to feed them without being physically present on the farm (Figure 12) [81]. Next, we constructed a received signal strength-based location system for grazing cattle that enabled monitoring the location of cattle in pastures in mountainous areas. Hence, we created two systems that are controllable via a smartphone: one to call cattle and the other to monitor their location. We are also creating other devices that support farmers. These systems should be very useful to farmers for controlling and monitoring cattle grazing.

\section{CONCLUSION}

The eating quality of beef produced by Japanese Black cattle is excellent, with more than $30 \%$ intramuscular fat and a significant concentration of MUFAs. However, there are numerous problems with wagyu beef production including high production costs, disposal of untreated excrement, the requirement for imported feed, and the potential food security risk resulting from viral diseases introduced by imported feed. Livestock

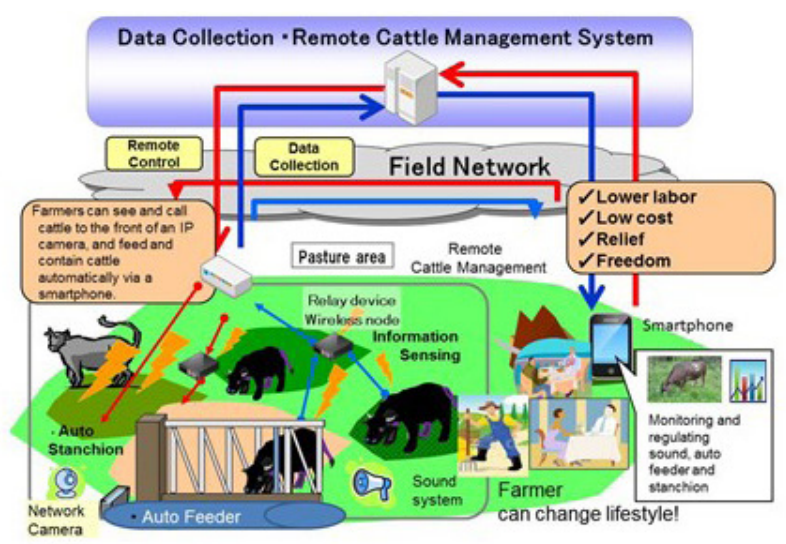

A. Overview of ICT control system via a smartphone for cattle in remote areas.

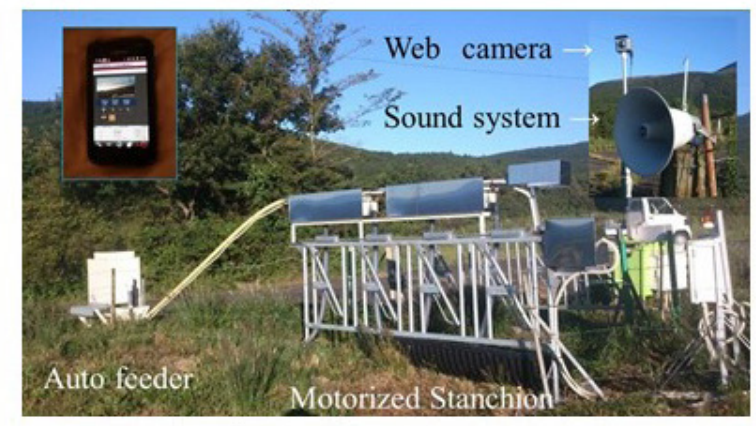

C. Auto stanchon system epidemics, such as BSE and FMD, have caused significant damage to the beef production industry in Japan. The dependence of Japanese Black beef production on imported grain has amplified concerns about future food safety not only because of known pathogens such as BSE and FMD but also because of unknown infectious diseases that may arise if contaminated feed is imported into Japan. The feeding system in Japan needs to shift to one that is more efficient and provides greater control for farmers and food security for consumers, as well as a healthier environment for residents. Animal welfare also needs to be considered, particularly because Japanese Black cattle are permanently housed in small pens and fed enormous quantities of concentrate and comparatively little roughage. As for the worldwide Japanese beef market, 248 cattle and more than 5,000 straws of frozen Japanese Black cattle semen have been exported to date, and Japanese Black cattle are being raised in 18 foreign countries [17]. Japanese Black cattle are highly regarded by cattle breeders in the United States, Canada, Germany, Austria, France, Thailand, China, Mexico, Australia, and other countries that aim to improve beef quality, especially marbling and tenderness. Meat from crossbred Wagyu cattle is also sold as Wagyu beef worldwide [17] and is relatively cheap com-

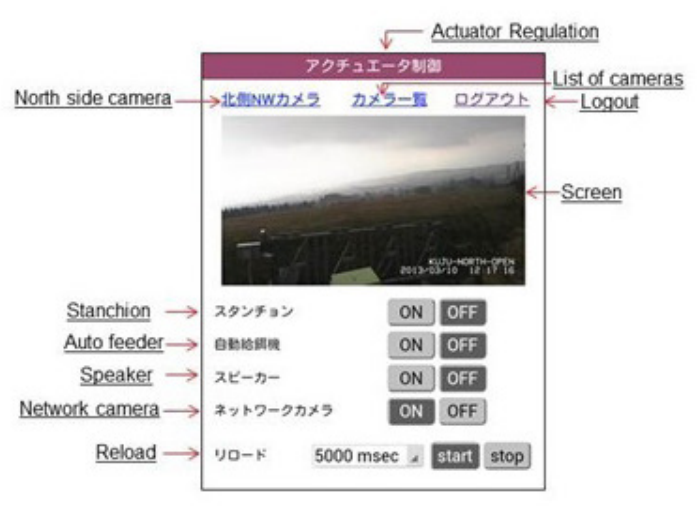

B. Actuator Control Screen on a smartphone.

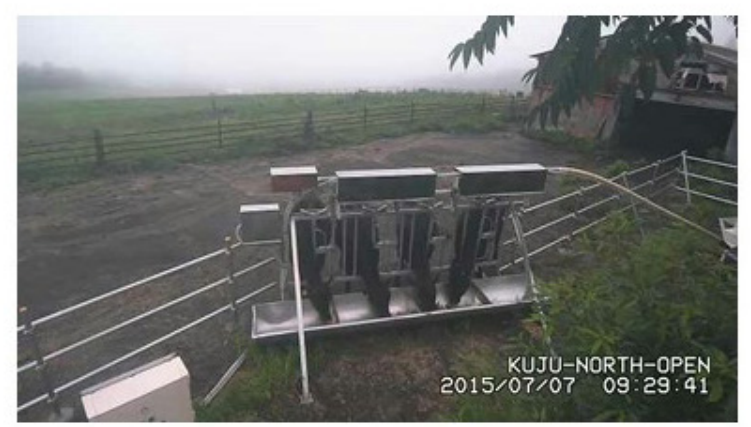

D. Picture of grazing cattle caught by auto stanchon.

Figure 12. Overview of ICT control system via a smartphone for cattle in remote areas and actuator control screen on a smartphone and the system [81]. (A) Overview of ICT control system via a smartphone for cattle in remote areas. (B) Actuator control screen on a smartphone. (C) Auto stanchon system. (D) Picture of grazing cattle caught by auto stanchon. 
pared with purebred Japanese Black beef. Considering the global distribution of purebred Japanese Black and crossbred Wagyu beef, new strategies are needed for Japanese farmers to produce and sell Japanese Black beef in the global marketplace.

Currently, we are developing a metabolic programming and an IoT management system for Wagyu beef production. If we succeed, we will produce safe, high-quality Wagyu beef using domestic grass and pasture resources while resolving the problem of how to utilize increasing areas of abandoned agricultural land and plant-based resources in Japan's mountainous areas.

\section{CONFLICT OF INTEREST}

We certify that there is no conflict of interest with any financial organization regarding the material discussed in the manuscript.

\section{ACKNOWLEDGMENTS}

The authors thank Mrs. Tetsuji Etoh, Yuji Shiotsuka and Ryoichi Fujino for assistance in animal and field managements, Drs. Paul Greenwood, Stephen Smith, and Hideyuki. Takahashi for scientific assistance in experiment. The authors wish to thank KAKENHI Grant Number 15380186, 20380150, 25660219, 25292162 and 26310312 of Japan Society for the Promotion of Science (JSPS) and CANON Foundation (R150089). The authors also thank Geoff Whyte, MBA, from Edanz Group (www.edanzediting.com/ac) for editing a draft of this manuscript.

\section{REFERENCES}

1. Hornstein I, Wasserman A. Sensory characteristics of meat. Part 2-Chemistry of meat flavor. In: Price JF, Schweigert BS, editors. The science of meat and meat products. 3rd ed. Westport, CT: Food and Nutrition Press; 1987. p. 329-47.

2. Wheeler TL, Cundiff LV, Koch M. Effect of marbling degree on beef palatability in Bos taurus and Bos indicus cattle. J Anim Sci 1994;72:3145-51.

3. Nishimura T, Hattori A, Takahashi K. Structural changes in intramuscular connective tissue during the fattening of Japanese black cattle: effect of marbling on beef tenderization. J Anim Sci 1999;77:93-104.

4. Horii H, Sakurai Y, Kanbe Y, et al. Relationship between Japanese beef marbling Standard numbers and intramuscular lipid in M. longissimus thoracis of Japanese Black steers from 1996 to 2004. Anim Sci J 2009;80:55-61 (in Japanese).

5. Sondik SB, Copperman N, Jacobson MS. Effects of a low-carbohydrate diet on weight loss and cardiovascular risk factors in over weight adolescents. J Pediatr 2003;142:253-8.
6. Johnston CS, Tjonn SL, Swan PD. High-protein, low-fat diets are effective for weight loss and favorably alter biomarkers in healthy adults. J Nutr 2004;134:586-91.

7. Morita S, Iwamoto H, Fukumitsu Y, et al. Histochemical studies on the skeletal muscles in fattened Mishima steers. Anim Sci J 2000;71:J51-9.

8. Gotoh T, Albrecht E, Teuscher F, et al. Differences in muscle and fat accretion in Japanese Black and European cattle. Meat Sci 2009;82:300-8.

9. Albrecht E, Gotoh, T, Ebara F, et al. Cellular conditions for intramuscular fat deposition in Japanese Black and Holstein steers. Meat Sci 2011;89:13-20.

10. May SG, Sturdivant CA, Lunt SK, Miller RK, Smith SB. Comparison of sensory characteristiics and fatty acid composition between Wagyu and crossbred and Angus steers. Meat Sci 1993;35:289-98.

11. Greenwood PL, Cafe LM, Hearnshaw H, et al. Long-term consequences of birth weight and growth to weaning for carcasss, yield and beef quality characteristics of Piedmontese- and Wagyu-sired cattle. Aust J Exp Agric 2006;46:257-69.

12. Greenwood PL, Cafe LM, Hearnshaw H, Hennessy DW, Morris SG. Consequence of prenatal and preweaning growth for yield of primal cuts from 30 months of-old Piedmontese- and Wagyu-sired cattle. Anim Prod Sci 2009;49:468-78.

13. Café LM, Hennessy DW, Hearnshaw H, Morris SG, Greenwood $\mathrm{PL}$. Influences of nutrition during pregnancy and lactation on birthweights and growth to weaning of calves sired by Piedmontese or Wagyu bulls. Aust J Exp Agric 2006;46:245-55.

14. Café LM, Hennessy DW, Hearnshaw H, Morris SG, Greenwood PL. Consequence of prenatal and preweaning growth for feedlot growth, intake and efficiency of Piedmontese and Wagyu-sired cattle. Anim Prod Sci 2009;49:461-7.

15.Zembayashi M, Nishimura K, Lunt DK, Smith SB. Effect of breed type and sex on the fatty acid composition of subcutaneous and intramuscular lipids of finishing steers and heifers. J Anim Sci 1995;73:3325-32.

16. Gotoh T, Takahashi H, Nishimura T, Kuchida K, Mannen H. Meat produced by Japanese black cattle and wagyu. Anim Front 2014;4:46-54.

17. Wagyu International [internet], Wagyu international: Australian Wagyu Association [cited 2013]. Wagyu International; Available from: http://www.wagyuinternational.com/wagyu.php

18. Villarroya F, Giralt M, Iglesias R. Retinoids and adipose tissues: metabolism, cell differentiation and gene expression. Int J Obes 1999;23:1-6.

19. Oka A, Maruo Y, Miki T, Yamasaki T, Saito T. Influence of Vitamin a on the quality of beef from the Tajima strain of Japanese Black cattle. Meat Sci 1998;48:159-67.

20. Nade T, Masuda Y, Misumi S, Fujita K. Effects of Vitamin A restriction on growth and carcass characteristics of Japanese Black steers measured by ultrasonic equipment. Anim Sci J 2007;78:161-6 (in Japanese). 
21. Japan Meat Grading Association (JMGA). Beef carcass trading standards. Tokyo, Japan: JMGA; 2014

22. Japan Meat Grading Association (JMGA). Beef carcass trading standards. Tokyo, Japan: JMGA; 1988

23. Ministry of Agriculture, Forestory and Fisheries (MAFF) [Internet], Statistics VIII. Livestock and poultry: number of farm households feeding livestock and number of livestock fed etc, MAFF [cited 2018 Apr]. Available from: http://www.maff. go.jp/e/data/stat/90th/index.html\#3

24. Pencharz BP. Protein and animo acids. In'Present knowledge in nutrition'. 10th ed. In: Erdman Jr JW, Macdonald IA, Zeisel $\mathrm{SH}$, editors. Singapore: International Life Sciences Institute; John Wiley \& Sons; 2012. pp. 69-82.

25. Mirae O, Kim EK, Jeon, BT, Yujiao T. Chemical compositions, free amino acid contents and antioxidant activities of Hanwoo (Bos taurus coreanae) beef by cut. Meat Sci 2016;119:16-21.

26. Sturdivant CA, Lunt DK, Smith GC, Smith SB. Fatty acid composition of subcutaneous and intramuscular adipose tissues and M. longissimus dorsi of Wagyu cattle. Meat Sci 1992;32:449-58.

27. Gotoh T, Olavanh S, Shiota M, et al. Relationship between myofiber type and fatty acid composition in skeletal muscles of Wagyu (Japanese Black) and Holstein cattle. In: Proceeding of 57th International Congress of Meat Science and Technology 2011; 2011 August 8-12: Ghent, Belgium.

28. Klont RE, Brocks L, Eikelenboom G. Muscle fiber type and meat quality. Meat Sci 1998;49:S219-29.

29. Iwamoto H, Ono Y, Goto T, et al. Comparative studies on the composition of muscle fiber types in Japanese Black, Japanese Brown and Holstein steers. Anim Sci Technol 1991;62:67482 (in Japanese).

30. Gotoh T, Histochemical properties of skeletal muscles in Japanese cattle and their meat production ability, review. Anim Sci J 2003;74:339-54.

31. Morita S, Iwamoto H, Fukumitsu Y, et al. Heterogeneous composition of histochemical fibre types in the different parts of $\mathrm{m}$. longissimus thoracis from Mishima (Japanese native) steers. Meat Sci 1999;54:59-63.

32. Solomon MB. Profile of fiber types in muscles from wild pigs native to the United States. Meat Sci 1985;13:247-54.

33. Rahelic S, Puac S. Fibre types in longissimus dorsi from wild and highly selected pig breeds. Meat Sci 1981;5:439-50.

34.Zembayashi M. Effects of nutritional planes and breeds on intramuscular-lipid deposition in M. longissimus dorsi of steers. Meat Sci 1994;38:367-74.

35. Nishimura T. The role of intramuscular connective tissue in meat texture. Anim Sci J 2010;81:21-7.

36. Yang A, Larsen TW, Powell H, Tume K. A comparison of fat composition of Japanese and long-termgrain-fed Australian steers. Meat Sci 1999;51:1-9.

37. Melton L, Amiri M, Davis W, Backus R. Flavor and chemical characteristics of ground beef from grass-, forage-grain- and grain-finished steers. J Anim Sci 1982;55:77-87.

38. Rudel L, Park S, Sawyer K. Compared with dietary monounsaturated and saturated fat, polyunsaturated fat protects African green monkeys from coronary artery athero-sclerosis. Arterioscler Thromb Vasc Biol 1995;15:2101-10.

39. Smith $S$. The animal fatty acid synthase: one gene, one polypeptide, seven enzymes. FASEB J 1994;8:1248-59.

40. Jenkins C. Lipid metabolism in the rumen. J Dairy Sci 1993;76: 3851-63.

41.Edwards R, Tove S, Blumer T, Barrick E. Effects of added dietary fat on fatty acid composition and carcass characteristics of fatting steers. J Anim Sci 1961;20:712-7.

42. Cabezas M, Hentges J, Moore J, Olson J. Effect of diet on fatty acid composition of body fat in steers. J Anim Sci 1965;24:5761.

43. Oka A, Iwaki F, Dohgo T, et al. Genetic effects on fatty acid composition of carcass fat of Japanese Black Wagyu steers. J Anim Sci 2002;80:1005-11.

44. Taniguchi M, Utsugi T, Oyama K, et al. Genotype of stearoylCoA desaturase is associated with fatty acid composition in Japanese Black cattle. Mamm Genome 2004;15:142-8.

45. Kim YC, Ntambi JM. Regulation of stearoyl-CoA desaturase genes: Role in cellular metabolism and preadipocyte differentiation. Biochem Biophys Res Commun 1999;266:1-4.

46. Yang A, Larsen TW, Smith SB, Tume RK. $\Delta 9$ desaturase activity in bovine subcutaneous fatty acid composition. Lipids 1999;34: 971-8.

47. Ohsaki H, Tanaka A, Hoashi S, et al. Effect of SCD and SREBP genotypes on fatty acid composition in adipose tissue of Japanese Black cattle herds. Anim Sci J 2009;80:225-32.

48. Ishii A, Yamaji K, Uemoto Y, et al. Genome Wide association study for fatty acid composition in Japanese Black cattle. Anim Sci J 2013;84:675-82.

49. Kelly MJ, Tume RK, Fortes M, Thompson JM. Whole-genome association study of fatty acid composition in a diverse range of beef cattle breeds. J Anim Sci 2014;92:1895-901.

50. Shimano H. Sterol regulatory element-binding proteins (SREBPs), transcriptional regulators of lipid synthetic genes. Prog Lipid Res 2001;40:439-52.

51.Hoashi S, Ashida N, Ohsaki H, et al. Genotype of bovine sterol regulatory element binding protein-1 (SREBP-1) is associated with fatty acid composition in Japanese Black cattle. Mamm Genome 2007;18:880-6.

52. Abe T, Saburi J, Hasebe H, et al. Novel mutations of the FASN gene and their effect on fatty acid composition in Japanese Black beef. Biochem Genet 2009;47:397-411.

53. Hoashi S, Hinenoya T, Tanaka A, et al. Association between fatty acid compositions and genotypes of FABP4 and LXR in Japanese Black cattle. BMC Genet 2008;9:84.

54. Matsumoto H, Sasaki K, Bessho T, et al. The SNPs in the ACACA gene are effective on fatty acid composition in holstein milk. Mol Biol Rep 2012;39:8637-44. 
55. Matsumoto H, Shimizu Y, Tanaka A, et al. The SNP in the promoter region of the bovine ELOVL5 gene influences economic traits including subcutaneous fat thickness. Mol Biol Rep 2013; 40:3231-7.

56. Matsumoto H, Nogi T, Tabuchi I, et al. The SNPs in the promoter regions of the bovine FADS2 and FABP4 genes are associated with beef quality traits. Livest Sci 2014;163:34-40.

57. Sasazaki S, Akiyama K, Narukami T, et al. UTS2R gene polymorphisms are associated with fatty acid composition in Japanese beef cattle. Anim Sci J 2014;85:499-505.

58. Inoue K, Kawamura T, Inuduka A, et al. Intensive fattening by shorttening period in japanese black steers. Bull Beef Cattle Sci 2000;68:48-54.

59.Zembayashi M, Inayama M. Fat partition and its distritbution in Japanese Black, Japanese Shorthorn and Holstein steer carcass. Jpn J Zootech Sci 1987;58:381-7.

60. Bocquier F, González-García E. Sustainability of ruminant agriculturein the new context: feeding strategies and features of animal adaptability into the necessary holistic approach. Animal 2010;4:1258-73.

61. Barker DJP, Eriksson JG, Forsén T, Osmond C. Fetal origins of adult disease: strength of effects and biological basis, Int J Epidemiol 2002;31:1235-9.

62. Gluckman PD, Hanson MA. Living with the past: evolution, development, and patterns of disease. Science 2004;305:17336.

63. Haugaard CT, Bauer MK. Rodent models of intarauterine growth restriction. Scand J Lab Anim Sci 2001;28:10-22.

64. Waterland RA, Garza C. Potential mechanisms of metabolic imprinting that lead to chronic disease. Am J Clin Nutr 1999; 69:179-97.

65. Waterland RA, Jirtle RL. Early nutrition, epigenetic changes at transposons and imprinted genes, and enhanced susceptibility to adult chronic diseases. Nutrition 2004;20:63-8.

66. Weaver ICG, Cervoni N, Champagne FA, et al. Epigenetic programming by maternal behavior. Nat Neurosci 2004;7: 847-54.

67. Aalinkeel R, Srinivasan M, Song F, Patel MS. Programming into adulthood of islet adaptatins induced by early nutritional intervention in the rat. Am J Physiol Endocrinol Metab 2001; 281:E640-8.

68. Srinivasan M, Laychock SG, Hill DJ, Patel MS. Neonatal nutrition:metabolic programming of pancreatic islets and obesity. Exp Biol Med 2003;228:15-23.

69. Waterland RA, Kellermayer R, Rached M-T, et al. Epigenomic profiling indicates a role for DNA methylation in early postnatal live development. Hum Mol Genet 2009;18:3026-38.

70. Waterland RA. Nutritional epigenetics. In: Erdman Jr JW, Macdonald IA, Zeisel SH, editors. Present knowledge in nutrition, 10th ed. Singapore: International Life Sciences Institute; John Wiley \& Sons; 2012. p. 14-26.
71. Jaenisch R, Bird A. Epigenetic regulation of gene expression: how the genome integrates intrinsic and environmental signals. Nat Genet 2003;33(Suppl.):245-54.

72. Canani RB, Di Costanzo M, Leone L, et al. Epigenetic mechanisms elicited by nutrition in early life. Nutr Res Rev 2011;24: 198-205.

73. Funston RN, Summers AF. Epigenetics: Setting up lifetime production of beef cows by managing nutrition. Annu Rev Anim Biosci 2013;1:339-63.

74. Mathers JC, McKay JA. Epigenetics-potential contribution to fetal programming. Adv Exp Med Biol 2009;646:119-23.

75.Scheffler JM, McCann MA, Greiner SP, et al. Early metabolic imprinting events increase marbling scores in fed cattle. J Anim Sci 2014;92:320-4.

76. Gotoh T, Fumita T, Etoh T, et al. Influence of metabolic imprinting on meat quality: impact of feed quality during early growth period on intramuscular adipogenesis in Holstein steers. In: Proceeding of XIIth AAAP animal science congress 2006; 2006 September 17-23: Busan, Korea: Korean Society of Animal Science \& Technology, Federation of Korean Societies of Animal Sciences; 2006. pp. 50.

77. Gotoh T, Etoh K, Saitoh K, et al. Metabolic imprinting effect in beef production: influence of nutrition manipulation during an early growth stage on carcass characteristics and intramuscular fat content of longissimus muscle in Wagyu (Japanese Black). In: Matteo Crovetto G, editor. Proceeding of the 3rd EAAP (European Federation of Animal Science) International Symposium on Energy and Protein Metabolism and Nutrition 2010; 2010 September 6-10: Parma, Italy. Waneningen, The Netherlands: Waneningen Academic Publishers; 2010. pp. 669-70.

78. Sithyphone K, Yabe M, Horita H, et al. Comparison of feeding systems: feed cost, palatability and environmental impact among hay-fattened beef, consistent grass-only-fed beef and conventional marbled beef in Wagyu (Japanese Black cattle). Anim Sci J 2011;82:352-9.

79. Gotoh, T. Potential of the application of epigenetics in animal production. Anim Prod Sci 2015;55:145-58.

80. Sithyphone K, Fujimura R, Etoh K, et al. Metabolic imprinting effect in beef production: influence of nutrition manipulation during an early growth stage on PPARg2 and PMRT5 expressions in the longissimus muscle in Wagyu (Japanese Black). In: Proceedings of the 8th developmental origins of health and disease (DOHaD) 2013; 2013 November 16-21: Singapore. Singapore: Cambridge University Press; 2013. pp. 566.

81. Gotoh T. Challenges of application of ICT in cattle management: remote management system for cattle grazing in mountainous areas of Japan using a smartphone, smart sensors and systems. In: Kyung CM, Yasuura H, Liu Y, Lin YL, editors. Innovations for medical, environmental, and IoT application. Switzerland: Springer International Publishing; 2016. p. 467-84. 